\title{
Modelling growth and bioaccumulation of Polychlorinated biphenyls in common sole (Solea solea)
}

\author{
M. Eichinger ${ }^{a}{ }^{*}$, V. Loizeau ${ }^{a}$, F. Roupsard ${ }^{a}$, A.M. Le Guellec ${ }^{a}$ and C. Bacher ${ }^{b}$ \\ a IFREMER, Département de Biogéochimie et Ecotoxicologie, Technopôle Brest-Iroise, Pointe du Diable, BP70, \\ 29280 Plouzané, France \\ b IFREMER, Département Dynamiques de l'Environnement Côtier, Technopôle Brest-Iroise, Pointe du Diable, \\ BP70, 29280 Plouzané, France \\ *: Corresponding author: M. Eichinger, Tel.: +33 2982246 79; fax: +33 2982245 48, email address : \\ eichingem@hotmail.com
}

\begin{abstract}
:
Experiments were performed on juvenile sole in controlled conditions in the aim of understanding how the biology of common sole may affect the accumulation and dilution of Polychlorinated biphenyls (PCBs). The fish were raised in optimal conditions and divided into two tanks: one control tank and one PCB tank. 4 PCB congeners were added to food for 3 months in the PCB tank; the soles were subsequently fed unspiked food for 3 months. Growth (length and weight) and PCB concentrations were monitored in both tanks and juvenile sole growth was not significantly affected by PCBs in our experimental conditions. We used the Dynamic Energy Budget (DEB) theory to model sole biology and paid special attention to model calibration through the wide use of data from the literature. The model accurately reproduced fish growth in both tanks. We coupled a bioaccumulation model to reproduce the concentration dynamics of the 4 PCB congeners used. This model did not require additional calibration and was dependent solely on the growth model and PCB concentrations in food. The bioaccumulation model accurately simulated PCB accumulation in fish, but overestimated PCB concentrations in fish during the dilution phase. This may suggest that in addition to PCB dilution due to growth, PCB concentrations decreased due to other PCB elimination mechanisms. Finally, we discussed potential improvements to the model and its future applications.
\end{abstract}

Keywords: Solea solea; Polychlorinated Biphenyls; Growth Model; Bioaccumulation Model; DEB Theory 


\section{INTRODUCTION}

The use of mechanistic models to evaluate and predict individual responses of living organisms to environmental disturbances and the impact of these disturbances on population dynamics is of considerable interest (Alunno-Bruscia et al., 2009). These models are already used for various marine research purposes, such as the reconstruction of food conditions for bivalve species (Freitas et al., 2009), the prediction of anchovy spawning duration according to environmental conditions (Pecquerie et al., 2009) and the analysis of contamination levels in hake from various study zones due to dietary evolution, according to hake length and various hake bolus contamination levels in each zone (Bodiguel et al., 2009). Mechanistic models can thus be used to resolve issues relating to organism feeding, growth, reproduction and contamination from the individual to the trophic level, and specifically for persistent and bioaccumulable contaminants in living organisms, like PCBs.

Polychlorinated biphenyls (PCBs) are synthetic organic chemicals forming a family of 209 congeners used for numerous industrial applications and in particular in the electrical power industry. PCBs are characteristic of chronic contamination from urban and industrial sources. They are highly stable, hydrophobic and persistent. They thus represent typically bioaccumulable compounds. They have been detected in all environmental compartments at concentrations ranging from picograms per litre in oceanic water to milligrams per kilogramme in the fatty tissue of marine mammals (Abarnou and Loizeau, 1994). These compounds provoke a wide range of toxicological responses depending on the position of their chlorine atoms (Ahlborg and Hanberg, 1994). In Europe, the use of PCBs for everyday applications has been prohibited since 1979. Recent studies have shown that the concentrations of seven PCB congeners have decreased in five fish species since 1997 in the Baltic Sea, with different patterns according to congeners and fish species (Szlinder-Richert et al., 2009). However, results of a chemical contamination monitoring program of the French 
1 coastline (RNO - French mussel monitoring network) highlighted the high levels of persistent

2 organic contaminants in estuaries. Coastal and estuarine ecosystems are highly productive

3 areas and contribute largely to the economic value of marine environments (Costanza et al.,

4 1997).

Flatfish use coastal habitats during the critical juvenile period, when their movements are limited (Koutsikopoulos et al., 1995; Riou et al., 2001). Their benthic lifestyle and the fact that their nurseries are located in coastal estuarine zones make them particularly vulnerable to chronic and accidental pollution (Mole and Norcross, 1998; Able 1999; Smith and Suthers, 1999). Common sole (Solea solea L.) are found from the coasts of Norway to Mauritania.

This highly-commercial benthic species is present throughout the coasts of France, including the English Channel and Mediterranean coasts. Various investigations have reported the effects of oil exposure on juvenile sole (Claireaux et al., 2004) and of specific PCB congeners on larvae (Foekema et al., 2008), but, to the best of our best knowledge, no studies to date have focused on the bioaccumulation patterns of PCBs and their effects on juvenile sole. Empirical approaches in aquatic systems often use the bioaccumulation factor (BAF), defined as being the ratio between compound concentrations in the organism and in its food (Hofelt and Shea, 1997; Ivanciuc et al., 2006). However, this method does not provide any insight into how these factors will evolve during the organism's lifetime, or how bioaccumulation processes differ according to species. Modelling is therefore necessary to understand how bioaccumulation differs according to organism physiology. Several authors

21 have developed bioaccumulation models describing PCB behaviour in aquatic food webs (Thomann and Connolly, 1984; Loizeau et al., 2001; Bodiguel et al.; 2009, Rashleigha et al., 2009). However, this approach requires adequate knowledge of the environment, which impacts growth and reproduction. This often proves difficult, especially if we are unfamiliar 
1 experimental study in controlled conditions, using measured food and PCB inputs, in order to

2 assess juvenile sole growth and PCB bioaccumulation.

The main purpose of this study was to calibrate a mechanistic model of sole growth and couple it to a PCB bioaccumulation model in order to understand how growth may affect PCB accumulation. This phase is necessary (1) if the model is to be used for subsequent in situ investigations, to assess nursery quality, or for predicting PCB elimination from the environment and (2) to incorporate the impact of contaminants on physiological responses. We chose the Dynamic Energy Budget (DEB) theory (Kooijman, 2000) to describe sole growth, in view of its genericity and mechanistic rules. This theory has been widely applied to and validated on an individual level for various marine organisms, ranging from bacteria (Eichinger et al., 2009) to bivalves (Pouvreau et al., 2006; Bourlès et al., 2009) and fish (van der Veer et al., 2001; Bodiguel et al., 2009; Pecquerie et al., 2009) and on the ecosystem level for a number of organisms (Maury et al., 2007; Grangeré et al., 2009). This model was calibrated and used for the study of sole by van der Veer et al. (2001). However, various uncertainties remain as regards its calibration, in particular as the study focused only on females and the majority of model parameters were deduced from plaice (Pleuronectes platessa) biology. We paid specific attention to model calibration, which was performed using large amounts of data from the literature. Model simulations were compared to juvenile growth data from our experiments and to published in situ growth curves, covering the entire sole life cycle. The bioaccumulation model was coupled to the energy allocation model. This approach was first used for the in situ study of PCB bioaccumulation by Bodiguel et al. (2009) and showed promising results. We compared PCB concentrations measured in sole throughout the course of the experiment to bioaccumulation model predictions. In our conclusion, we put forward various assumptions that may explain the discrepancies found 
1 between model simulations and measurements, and presented future improvements and

2 applications for the model.

\section{MATERIAL AND METHODS}

\subsection{Experiment design}

Our experiments were performed on juvenile sole (G0) obtained from a farm (Solea

BV, Netherlands). The fish showed very low levels of PCB at the outset: $[\mathrm{CB} 105]=0.8 \mathrm{ng} \cdot \mathrm{g}^{-1}$ of wet weight, $[\mathrm{CB} 118]=1.9 \mathrm{ng} \cdot \mathrm{g}^{-1}$ of wet weight, $[\mathrm{CB} 149]=2.0 \mathrm{ng} \cdot \mathrm{g}^{-1}$ of wet weight and

$9 \quad[\mathrm{CB} 153]=4.1 \mathrm{ng} \cdot \mathrm{g}^{-1}$ of wet weight.

The sole were raised in optimal conditions in terms of temperature $\left(19^{\circ} \mathrm{C}\right)$, oxygenation (> 80\%), fish density $\left(\sim 2 \mathrm{~kg} \cdot \mathrm{m}^{-2}\right)$, photoperiod $(12: 12)$ and food (ad libitum) (Table 1) (Imsland et al., 2003; Schram et al., 2006). PCBs were artificially added to fish food (DAN-EX 1362, Dana Feed®, Horsens, Denmark) in order to investigate the bioaccumulation properties of PCBs and their potential effects on sole. In view of the very low solubility of PCBs in water, we were obliged to coat them with solvent (iso-octane: $160 \mathrm{ml}$ for every $4 \mathrm{~kg}$ of food granules) before incorporating them in the food. After coating, the granules were evaporated under a nitrogen jet to remove the maximum amount of solvent. Contamination efficiency was then measured for each congener (measured concentration vs theoretical concentration). The initial group of sole was separated into 2 tanks with equivalent fish densities (Table 1): one control tank (C) and one PCB tank. Mean initial lengths were $12.4 \pm$

$211.4 \mathrm{~cm}$ and $12.0 \pm 1.3 \mathrm{~cm}$ for the $\mathrm{C}$ and PCB tanks respectively; mean initial weights were $19.2 \pm 6.1 \mathrm{~g}$ and $16.0 \pm 4.6 \mathrm{~g}$ for the $\mathrm{C}$ and PCB tanks respectively (Table 1). We selected the four PCB congeners most commonly found in the environment: CB105, CB118, CB149 and CB153. Concentrations in food were measured for each congener (see Table 1). The experiment lasted 6 months overall, comprising a 3-month contamination period and a 3- 
month non contamination period in the PCB tank: after feeding the sole with spiked granules, we subsequently studied their decontamination dynamics by feeding them unspiked granules coated with the same amount of solvent.

\subsection{Measurements}

We monitored sole growth in both tanks through individual biometric measurements of total length $(L$ in $\mathrm{cm})$ and total wet weight ( $W_{W}$ in $\mathrm{g}$ ) on sampling days $0,4,8,28,56,84$ (last day of feeding with spiked food), 88, 91, 98, 112, 140 and 168 (Table 1).

We divided the fish from the PCB tank into 3 groups of 4 to 11 fish on each sampling day due to analytical constraints. We then took liver, gonad and muscle samples from each group. We quantified PCB in muscle only to estimate whole fish concentrations. PCB measurements in liver and gonads were used to monitor PCB distribution according to exposure time (outside the scope of this study). The collected organs were frozen at $-80^{\circ} \mathrm{C}$, dried, then ground to obtain a fine homogeneous powder. Water content was estimated on the basis of weight loss after freeze-drying. To perform PCB quantification, a precisely-weighed amount of powdered material (typically around $2 \mathrm{~g}$ for muscles) was solvent-extracted with a hot Soxhlet extraction device (Soxtec) for 1.5 hours using a hexane:acetone mixture (80:20). The solvent was then carefully and entirely evaporated using a rotavapor. The residue was weighed to assess the total lipid content of each muscle group (Bodin et al., 2007). The extracts were cleaned prior to final instrumental analysis using gas chromatography with an electron capture detector on a HP 5890 series II equipped with a CP-Sil19 capillary column in the optimal conditions described by Jaouen-Madoulet et al. (2000) and Bodiguel et al. (2009). PCBs were individually quantified using a standard solution.

We also performed independent experiments to quantify PCB in muscle, liver, gonads, digestive tract, kidney and carcass (corresponding to the remains of the animal) of individual 
1 sole fed with PCB-spiked food according to the same protocol (data not shown). PCB

2 concentrations (ng.g $\mathrm{g}^{-1}$ of wet weight) were calculated as the sum of PCB quantified in each

3 tissue type divided by sole total wet weight. PCB concentrations (ng. $\mathrm{g}^{-1}$ of lipids) were also

4 calculated for each tissue type and showed equivalent values notwithstanding tissue type. We

5 therefore assumed that PCB concentrations (ng. $\mathrm{g}^{-1}$ of lipids) were homogeneous throughout

6 all tissues. On the basis of this result, we established a relationship between total lipids (\%)

7 and lipids in muscle (\%) in order to calculate total PCB concentrations (ng. $\mathrm{g}^{-1}$ of wet weight,

8 required for modelling purposes) from PCB quantified in muscle (ng. $\mathrm{g}^{-1}$ of lipids) as follows:

9

10

11

$$
\left[C B^{*}\right]_{f i s h}=\left[C B^{*}\right]_{M} \frac{\% T L}{100}
$$

$$
\% T L=5.17 \operatorname{Ln}(\% L M)+0.84
$$$$
\mathrm{R}^{2}=0.82
$$

where $\left[C B^{*}\right]_{f i s h}$ represents the total concentration (ng.g $\mathrm{g}^{-1}$ of total wet weight) of the congener $\mathrm{CB}^{*}(*=105,118,149$, or 153$)$

$\left[C B^{*}\right]_{M}$ represents the concentration in muscle (ng. $\mathrm{g}^{-1}$ of lipids) of the congener $\mathrm{CB}^{*}$ $(*=105,118,149$, or 153$)$

$\% T L$ is the percentage of total lipids

$\% L M$ is the percentage of lipids measured in muscle

\subsection{Model description}

We used the DEB theory (Kooijman, 2000) to model sole growth. Our model was mostly based on a previous model used for flatfish, including the common sole (van der Veer et al., 2001). Model notations and state variables are summarised in Tables 2 and 3 respectively; Table 4 provides a full parameter description.

The DEB theory is based on the concept that animals comprise three compartments or state variables: structural volume $(V)$, energy reserves $(E)$ and energy reserves allocated to 
1 reproduction $\left(E_{R}\right)$ (Table 3). Within the DEB framework, fluxes are represented by the

2 notation $\dot{p}_{*}$, whereby $*$ represents the associated process (Table 2$)$. Food $(X)$ is ingested $\left(\dot{p}_{X}\right)$

3 as a function of organism surface area [eq. (2)] and assimilated $\left(\dot{p}_{A}\right)$ in the reserve

4 compartment $(E)$. Assimilation and ingestion are differentiated according to assimilation

5 efficiency ( $y_{E X}$ ) [Table 4 and eq. (3)]. The energy reserve is stored in $E$, and is considered as

6 the difference between assimilation and mobilisation [eq. (4)]. A fixed proportion ( $\kappa)$ of the

7 mobilised reserve $\left(\dot{p}_{C}\right)$ is used for growth of the structural volume $(V)$. Maintenance $\left(\dot{p}_{M}\right)$

8 systematically has priority over growth of the structural volume ( $\left.\dot{p}_{G}\right)$ [Fig. 1 and eq. (5)]. The

9 complementary proportion $(1-\kappa)$ is used for development or reproduction, by providing

energy to $E_{R}$. Maturity maintenance ( $\left.\dot{p}_{J}\right)$ systematically has priority over growth of the

11 reproduction buffer $\left(\dot{p}_{R}\right)$ [Fig. 1 and eq. (6)]. We took the juvenile and adult stages of sole

12 only into account, in accordance with our data sets. The switch from juvenile to adult is a

13 function of the maturity volume ( $V_{P}$, where $p$ represents puberty). According to the DEB

14 theory, the energy spent on juvenile development is spent on reproduction in adults

15 (Kooijman, 2000, p. 87). The energy allocated to reproduction $\left((1-\kappa) \dot{p}_{C}\right)$ therefore results in

16 an increase in gonad wet weight in adult fish only (when $\left.V>V_{P}\right)$. For juvenile sole $\left(V<V_{P}\right)$,

17 we stated that the energy allocated to development from $\left((1-\kappa) \dot{p}_{C}\right)$ serves to increase the

18 level of complexity, and consequently does not result in a weight increase. This is modelled

19 by implementing a cost $\left(\kappa_{R}\right)$ of $100 \%$ for energy transfer from $E_{R}$ to gonads. When sole are

20 adult $\left(V>V_{P}\right)$, energy allocated to $E_{R}$ results in an increase in gonad wet weight with a cost

$21 \kappa_{R}$. Energy in gonads is converted to gonad wet weight using an energy-weight converter

22 (Table 4). We used a conversion factor from total wet weight to egg numbers (egg) to

23 estimate egg production. Maturity maintenance is $\dot{p}_{J}=\left[\dot{p}_{M}\right] \min \left(V_{P}, V\right)$, meaning that it is 
1 proportional to actual volume when the sole are juvenile and to maturity volume when they

2 are adult: in juvenile soles, maturity maintenance associated with complexification must

3 increase in proportion to volume, whereas complexification is complete in adult fish, hence

4 justifying a constant maturity maintenance value from this point onwards. Equations 2-8

5 describe the sole growth model in full. In the DEB theory, parameters shown in square

6 brackets [ ] are volume-specific; parameters shown in standard brackets \{\} are surface area-

$7 \quad$ specific (Table 2).

$8 \quad \dot{p}_{X}=\left\{\dot{p}_{X_{M}}\right\} f V^{2 / 3}$

(2) (Kooijman, 2000; van der Veer et al., 2001)

$9 \dot{p}_{A}=y_{E X} \dot{p}_{X}$

$10 \quad \frac{d E}{d t}=\dot{p}_{A}-\dot{p}_{C}$

$11 \frac{d V}{d t}=\frac{\kappa \dot{p}_{C}-\left[\dot{p}_{M}\right] V}{\left[E_{G}\right]}$

$12 \frac{d E_{R}}{d t}=(1-\kappa)\left(\dot{p}_{C}-\frac{\dot{p}_{J}}{\kappa}\right)$

$13 \dot{p}_{C}=\frac{\frac{\left[E_{G}\right]}{\left[E_{m}\right]} y_{E X}\left\{\dot{p}_{X_{M}}\right\} V^{-1 / 3}+\left[\dot{p}_{M}\right]}{\frac{\left[E_{G}\right]}{E}+\frac{\kappa}{V}}$

$14 \dot{p}_{J}=\left[\dot{p}_{M}\right] \min \left(V_{P}, V\right)$

Rates are influenced by the environment. For instance, food influences ingestion (and

16 thus assimilation) fluxes via the variable food density ( $f$ ), which ranges from 0 to 1 , is

17 dimensionless and quantifies food availability. Temperature influences ingestion and

18 maintenance rates. We used the Arrhenius correction function to simulate the impact of

19 temperature on these rates:

$20 \quad \dot{p}_{*(T)}=\dot{p}_{*(T 1)} \exp \left(\frac{T A}{T 1}-\frac{T A}{T}\right)$ 
where $T A$ is the Arrhenius temperature

$T 1$ is the reference temperature at which the rate has been estimated $T$ is the actual temperature $\dot{p}_{*(T)}$ is the rate $\left(\left[\dot{p}_{M}\right]\right.$ or $\left.\left\{\dot{p}_{X_{M}}\right\}\right)$ at the actual temperature $T$ $\dot{p}_{*(T 1)}$ is the rate at the reference temperature $T 1$

\subsection{Comparison of model outputs and data}

The model state variables do not correspond to measurable quantities. In order to determine how structural volume relates to length, we used the dimensionless shape coefficient $\delta$ (Kooijman, 2000, p. 23): $V=(\delta L)^{3}$ where $V$ is the structural volume $\left(\mathrm{cm}^{3}\right)$ and $L$ is the modelled total length $(\mathrm{cm})$ (Table 3$)$. The energy reserve compartment $E$ is expressed in energy in the model (Table 3). As lipids are very rapidly mobilised after the start of starvation experiments on common sole (Richard et al., 1983), we stated that a large proportion of $E$ is composed of lipids. We therefore used an energy-weight conversion for $E$ that was slightly lower than the energyweight conversion for lipids: $\mu_{E}=30000 \mathrm{~J} \cdot \mathrm{g}^{-1}$ (Table 4) and obtained the reserve weight using the following formula: $W_{E}=\frac{E}{\mu_{E}}$. The reproduction buffer $E_{R}$ is also energy-based (Table 3). We considered that in adult sole, this compartment relates to gonad wet weight $\left(W_{G}\right)$ and is converted to weight with the energy-weight parameters $\mu_{G F}$ for females and $\mu_{G M}$ for males: $W_{G}=\frac{E_{R}}{\mu_{G^{*}}}$. Different gonad conversions were used as we presumed that female gonads had a higher lipid content and thus a higher energy-weight conversion value (Table 4). 
The total wet weight $W_{W}$ of an individual is the sum of the three DEB compartments

2 after their conversion to weight: $W_{W}=V+W_{E}+W_{G}$ (Table 3), where $V$ represents volume

3 with a density of 1 g.cm ${ }^{-3}$ (van der Veer et al., 2001). After calculating $W_{W}$, we estimated the

4 number of eggs produced by the sole by dividing $W_{W}$ by the egg parameter, corresponding to

5 the number of eggs per $1 \mathrm{~g}$ of wet weight (Table 4 ).

\subsection{Model calibration}

\subsubsection{Calibration strategy}

Data on juvenile growth from our experiments were insufficient for accurate calibration of the DEB model. We therefore utilised numerous data sets from the literature and a small number of observations from our data sets to calibrate the biological parameters of the DEB model. Once parameterisation was done, we estimated food density $(f)$ as the value that best fitted our juvenile wet weight growth curves. We initially estimated parameter values related to the volume-length relationship, ingestion, assimilation, maintenance and temperature impact on the basis of laboratorycontrolled experiments. These parameters were individually calibrated using one data set for each process (see below). We then used these estimated parameter values to numerically calibrate the remaining parameters on the basis of the complete growth curves (length and weight of juveniles and adults) of soles collected in Douarnenez Bay (French Atlantic Coast) (Deniel, 1981). This author also provided information on length at maturity and egg

21 production, hence enabling us to calculate the $V_{P}\left(\mathrm{~cm}^{3}\right)$ and $e g g$ parameters. 
1 The shape coefficient was estimated from C tank data as $\delta=\frac{W_{W}^{1 / 3}}{L}$. It is often assumed

2 that reserve weight is negligible in comparison to structural weight; $W_{W}$ is thus equivalent to

$3 V$ with a density of $1 \mathrm{~g} . \mathrm{cm}^{-3}$ and may be used to estimate $\delta$ (van der Veer et al., 2001).

4 However, for greater accuracy, we used the $W_{W}-L$ relationship for thinner individuals to

5 estimate $\delta$, so that reserve weight really was negligible in those individuals. The slope of

$6 \quad \frac{W_{W}^{1 / 3}}{L}$ versus $L$ was therefore equal to $\delta$ in these individuals.

8 2.5.3. Maximum specific ingestion rate $\left\{\dot{p}_{X_{M}}\right\}$ and Arrhenius temperature TA

We used daily food intake data as a function of length in young sole reared ad libitum with fresh mussels at a constant temperature in different tanks (from 10 to $26^{\circ} \mathrm{C}$ ) (Fonds and

11 Saksena, 1977) to estimate $\left\{\dot{p}_{X_{M}}\right\}$ and $T A$ (see their Fig. 1). We used a conversion factor of $1218750 \mathrm{~J} . \mathrm{g}^{-1}$ of dry weight to convert the weight of ingested mussels into energy (Fonds et al., 13 1989) and assumed that mussel water content was $80 \%$. We hence obtained daily ingested 14 energy $\left(\dot{p}_{X}\right)$ by multiplying the weight of ingested mussels by $3750 \mathrm{~J}^{-1} \mathrm{~g}^{-1}$ of wet weight. We 15 used data from all tanks to estimate $\left\{\dot{p}_{X_{M}}\right\}$ and TA simultaneously using equations (2) and (9): $\left\{\dot{p}_{X_{M}}\right\}=\frac{\dot{p}_{X}}{f V^{2 / 3}}=\frac{\dot{p}_{X}}{f(\delta L)^{2}} \quad$ and $\left\{\dot{p}_{X_{M}}\right\}_{(T)}=\left\{\dot{p}_{X_{M}}\right\}_{(T 1)} \exp \left(\frac{T A}{T 1}-\frac{T A}{T}\right)$, where $T 1=283 \mathrm{~K}$ 17 is the reference temperature (Table 4), $\dot{p}_{X}$ is the daily food intake converted into energy (J.d ${ }^{-}$ $\left.{ }^{1}{ }^{1}\right), f=1$ (ad libitum), $L$ values were provided by the data and $\delta$ was estimated previously. 
We used different assimilation efficiency values depending on whether environmental

2 (natural food) or experimental (artificial food) data were used. For in situ applications (Deniel data, 1981), we assumed that $y_{E X}=0.8$, as the overall loss in faeces is often supposed to be

$420 \%$ on average in wild fish (van der Veer et al., 2001). For experimental applications, we estimated that $y_{E X}$ was the ratio between metabolisable food energy and total food energy (DAN-EX 1362, Dana Feed®, Horsens, Denmark).

\subsubsection{Maintenance rate $\left[\dot{p}_{M}\right]$}

We used standard metabolic rate (SMR) data (Lefrançois and Claireaux, 2003) to

estimate the maintenance rate $\left[\dot{p}_{M}\right]$. SMR supports maintenance activities such as ventilation and osmoregulation and corresponds to the oxygen consumption of a resting, fasting, and non-maturing fish (Fry, 1971). It therefore adequately matched the maintenance rate defined

13 by the DEB theory. SMR measurements $\left(\mathrm{mg} \mathrm{O}^{2} \cdot \mathrm{kg}^{-1} \cdot \mathrm{h}^{-1}\right)$ were converted into energy values $\left(\mathrm{J} . \mathrm{cm}^{-3} \cdot \mathrm{d}^{-1}\right)$ using the energy balance of respiration, which provides a true reflection of energy consumption. We used the value of the thermal coefficient of oxygen $(19.8 \mathrm{~kJ})$, the chemical properties of dioxygen and a density of $1 \mathrm{~g} . \mathrm{cm}^{-3}$ for structural volume to obtain a conversion factor of 0.7 for the transformation of SMR measurements into energy values: $\left[\dot{p}_{M}\right]\left(\mathrm{J} \cdot \mathrm{cm}^{-3} \cdot \mathrm{d}^{-1}\right)=0.7 \operatorname{SMR}\left(\mathrm{mgO}^{2} \cdot \mathrm{kg}^{-1} \cdot \mathrm{h}^{-1}\right)$. Lefrançois and Claireaux (2003) measured SMR for temperatures ranging from $4^{\circ} \mathrm{C}$ to $26^{\circ} \mathrm{C}$ (see their Fig. 2b), which allowed the simultaneous estimation of $\left[\dot{p}_{M}\right]$ and $T A$ with their data set.

\subsubsection{Kappa ( $\kappa)$ estimation}

In DEB models, the following relationship applies when organisms reach their

24 maximum length $\left(L_{m}\right)$ and maximum reserve density $\left(E / V=\left[E_{m}\right]\right)$ in a given 
1 environment: $L_{m}=\kappa f \frac{y_{E X}\left\{p_{X m}\right\}}{\left[p_{M}\right]}$ (Kooijman, 2000; van der Veer et al., 2001). Using the

2 growth curves of sole from Douarnenez Bay (French Atlantic coast) (Deniel, 1981), we

3 estimated food density $(f)$ as being the ratio between the mean maximum lengths (after

4 inflection of the growth curve) of the data set and the maximum length ever observed $(70 \mathrm{~cm}$,

5 http://www.fishbase.org/). We obtained a value of $f=0.70$, which we considered as constant

6 for this data set. $L_{m}$ (mean values after the inflection of the growth curve) for males and

7 females were deduced from the same growth curves, allowing $\kappa$ estimation from the previous 8 equation for each sex.

9

2.5.7. Maturity volume $\left(V_{P}\right)$, number of eggs per gram of wet weight (egg), costs of structure

$11\left(\left[E_{G}\right]\right)$, and maximum energy density $\left(\left[E_{m}\right]\right)$

Some DEB parameters, such as volume at first maturity $\left(V_{P}\right)$ and number of eggs per

13 gram of wet weight (egg), correspond to biological quantities. Their values were taken from

14 Deniel (1981). Because sole for this data set were collected from Douarnenez Bay, we took

15 into account annual and sinusoidal temperature variations at that sampling site. We supposed

16 that temperature varied between $8^{\circ} \mathrm{C}$ and $18^{\circ} \mathrm{C}$ in bottom waters (Quiniou, 1986); this

17 variation was taken into account in the calibration process.

Spawning was not mechanistically modelled, as the processes regulating spawning are

mostly unknown. It was estimated that sole hatched once a year in Douarnenez Bay, on approximately February $1^{\text {st }}$ (Deniel, 1981). We therefore considered that sole hatched every

21365 days once they reached their maturity volume. Hatching was simulated via an empty $E_{R}$.

22 Finally, $\left[E_{G}\right]$ and $\left[E_{m}\right]$ were estimated using the least squares regression method against 23 growth and reproduction data from Deniel (1981), taking into account all values of previously 
1 estimated parameters and environmental factors ( $f$ and temperature). Little information is

2 available on male growth (only total length data) compared to female growth, but the DEB

3 theory supposes that $\left[E_{G}\right]$ and $\left[E_{m}\right]$ values are identical for both sexes (Table 4). We

4 calculated the sum of square deviations as being the sum of square deviations between

5 simulated and observed male lengths, female lengths and female total wet weight divided by

$610^{3}$ (to standardise the sum of weights with the sums of lengths). Due to the very low number

7 of observations available on female wet weight, we also used female total wet weight

8 estimated from the size-weight relationship given by Deniel (1981).

9

\subsection{8. f estimation from experimental data}

As all parameters were calibrated using independent data sets and our experimental

\subsection{The bioaccumulation model}

The bioaccumulation model was built on the basis of the following three principles: (1) as PCBs were included in food and are lipophilic, the only potential PCB source in the model was food. As the soles came from a farm, they showed very low PCB concentrations at the outset of the experiment; the values provided in 2.1 were utilised as initial conditions for the model; (2) due to the lipophilic nature of PCBs, they were bound to the reserve compartment - mainly composed of lipids - after assimilation; (3) as experimental growth curves did not show any significant differences between both tanks (see 4.4), we did not add 
1 any PCB impact on sole physiological functions. PCBs were not therefore metabolised in the

2 model and accumulated in the reserve compartment only (Fig. 1). PCB kinetics are a function of the assimilation flux $\left(\dot{p}_{A}\right)$ and of two parameters [eq.

4 (10)], which were measured experimentally: PCB concentrations in food $\left[C B^{*}\right]_{f}$ given in

5 Table 1 and the energy content of food $\left(\mu_{f}\right)$ mentioned on food bags (Table 4). PCB

6 concentrations in fish $\left(\left[C B^{*}\right]_{f i s h}\right)$ were finally estimated by dividing the previously estimated

7 PCB quantity at each time interval by the total wet weight [eq. (11)]:

$$
\begin{aligned}
& 8 \quad \frac{d C B_{f i s h}^{*}}{d t}=\frac{\left[C B^{*}\right]_{f}}{\mu_{f}} \dot{p}_{A} \\
& 9 \quad\left[C B^{*}\right]_{f i s h}=\frac{C B_{f i s h}^{*}}{W_{W}}
\end{aligned}
$$

\section{3. RESULTS}

\subsection{Calibration}

$$
\text { We plotted shape coefficient values against } L \text { values and estimated } \delta \text { as being the }
$$

14 slope of the line $\frac{W_{W}^{1 / 3}}{L}=f(L)$ for the thinner fish from the $\mathrm{C}$ tank, assumed to be fish from the smallest third (Fig. 2). We obtained a value of $\delta=0.204$ (Table 4). We estimated $\left\{\dot{p}_{X_{M}}\right\}$

16 and $T A$ at the reference temperature $T 1=283 \mathrm{~K}$ using a regression routine against experimental data on the daily food ingestion of juvenile sole (Fonds and Saksena, 1977). We obtained values of $460 \mathrm{~J} . \mathrm{cm}^{-3} \cdot \mathrm{d}^{-1}$ and $4700 \mathrm{~K}$ for $\left\{\dot{p}_{X_{M}}\right\}$ and TA respectively (Table 4). The

19 plot of $\left\{\dot{p}_{X_{M}}\right\}_{(T)}=\left\{\dot{p}_{X_{M}}\right\}_{(T 1)} \exp \left(\frac{T A}{T 1}-\frac{T A}{T}\right)$ for the 5 temperatures used in the experiments 
1 showed very good agreement with the mean experimental $\left\{\dot{p}_{X_{M}}\right\}$ (Fig. 3a). $y_{E X}$ was

2 estimated at 0.8 for in situ applications and as the ratio between metabolisable food energy

$3 \quad\left(17211 \mathrm{~J} . \mathrm{g}^{-1}\right)$ and total food energy $\left(21612{\mathrm{~J} . \mathrm{g}^{-1}}^{-1}\right.$ for experimental applications. We also

4 obtained $y_{E X}=0.8$ (Table 4). The maintenance rate $\left[\dot{p}_{M}\right]$ was estimated at $18.1 \mathrm{~J} . \mathrm{cm}^{-3} \cdot \mathrm{d}^{-1}$

5 using data on SMR (Lefrançois and Claireaux, 2003) at the reference temperature $T 1=283 \mathrm{~K}$.

6 These data were obtained from experiments conducted at 6 temperatures $\left(4^{\circ} \mathrm{C}\right.$ to $\left.26^{\circ} \mathrm{C}\right)$ and

7 thus allowed a second estimate of $T A$ at $4400 \mathrm{~K}$, i.e. very similar to our estimate made with

8 ingestion data. We simulated the equation $\left[\dot{p}_{M}\right]_{(T)}=\left[\dot{p}_{M}\right]_{(T 1)} \exp \left(\frac{T A}{T 1}-\frac{T A}{T}\right)$ with this

9 estimated $T A$ value and obtained a very good concomitance with experimental data on SMR

10 (Fig. 3b). We finally used an intermediate value for $T A(4550 \mathrm{~K})$, between the estimates made

11 from ingestion data and SMR data. Using this value, we also obtained good coherency

12 between eq. (9) and experimental data of $\left\{\dot{p}_{X_{M}}\right\}$ and $\left[\dot{p}_{M}\right]$ at different temperatures (Fig. 3a

13 and $b$ ). Using the maximum length equation and previously estimated parameter values, we

14 obtained $\kappa$ values of 0.64 and 0.70 for males and females respectively.

15 Length at first maturity was found to be $15 \mathrm{~cm}$ and $23 \mathrm{~cm}$ for males and females respectively (Deniel, 1981), giving $V_{p}$ values of $29 \mathrm{~cm}^{3}$ and $103 \mathrm{~cm}^{3}$ for males and females

17 respectively with our estimated $\delta$ value (Table 4). The value of the egg parameter was 550 eggs.g ${ }^{-1}$ of wet weight (Deniel, 1981). $\left[E_{G}\right]$ and $\left[E_{m}\right]$ were calibrated using the previously estimated parameters and by searching the minimum square deviation between model outputs and growth curves from Deniel (1981). The map of square deviations between model outputs

21 and the data exhibited numerous potential values for $\left[E_{G}\right]$ and $\left[E_{m}\right]$, with values ranging

22 from 5000 to $8000 \mathrm{~J} . \mathrm{cm}^{-3}$ for $\left[E_{G}\right]$ and $\left[E_{m}\right]$ values ranging from 3000 to $7000 \mathrm{~J} . \mathrm{cm}^{-3}$ (not

23 shown). For this reason, we finally took $\left[E_{G}\right]=7000 \mathrm{~J} . \mathrm{cm}^{-3}$ as in van der Veer at al. (2001) 
1 and estimated $\left[E_{m}\right]$, using this $\left[E_{G}\right]$ value, as the least square deviation between model

2 outputs and growth curves. We then obtained $\left[E_{m}\right]=2903{\mathrm{~J} . \mathrm{cm}^{-3}}^{-3}$ (Table 4).

3

\subsection{Model application for in situ conditions}

Model simulations coincided well with in situ data on male and female total lengths (Fig. 4a) and female total wet weight (Fig. 4b). The oscillations obtained during total weight simulations were due to spawning, which occurred every 365 days. Reproduction was less accurately simulated by the DEB model: gonad weight was slightly overestimated for a given total weight during the juvenile phase and the model did not reach maximum observed gonad weights (Fig. 4c). Modelled annual egg production exhibited good agreement with observations, but did not reach the maximum observed levels (Fig. 4d). Maturity (defined here as the start of the increase in gonad weight and first egg production) occurred at 2 years for the modelled females (Fig. 4c and d). Model simulations showed that males also reached maturity in their $2^{\text {nd }}$ year (simulations not shown). As little information was available on reproduction, including maturation, ovarian development and spawning we did not attempt to improve parameter calibration for this part of the model. Reproduction did not match in situ observations but this did not affect subsequent results, as the experiments were based on juvenile fish (age G0) that had not started reproducing.

\subsection{Model application for experimental conditions}

As $f$ was estimated as the mean value obtained with male and female simulations, we therefore presented the data as a single group of individuals and compared them with both simulations (Fig. 5 and 6 ). We obtained $f$ values of 0.68 for the $\mathrm{C}$ tank and 0.74 for the PCB tank. With the exception of these values, we used exactly the same parameter values as those for simulations on Deniel (1981) data. As the last parameter was calibrated on total wet 
1 weight data for each tank, the model simulations showed a very good match with weight data

2 for both the C (Fig. 5b) and PCB tanks (Fig. 6b). The model slightly overestimated total

3 length measurements in both tanks, but did not exceed observed standard deviations (Fig. 5a

4 and $6 a)$.

\subsection{Bioaccumulation model simulations}

As PCB measurements were performed on each sampling day on three groups of fish

(4 to 11 individuals per group and 1 measurement per group), we compared model outputs to the values of the three PCB concentration measurements (Fig. 7), rather than to a mean PCB concentration, which is meaningless over three values. We observed highly scattered PCB concentrations (Fig. 7), hence justifying this approach. In order to understand how this scatter influenced model comparison with experimental observations, we also compared measured total wet weights and [CB153] (ng. ${ }^{-1}$ wet weight) for each group to their modelled values (Fig. 8).

The bioaccumulation model coupled to the growth model was applied to each PCB congener included in food; the only difference between the models being congener concentration in food (Table 1). PCB measurements on the 3 groups of fish were less scattered during the accumulation phase versus the non contamination phase. The model properly reproduced the accumulation phase between days 0 and 84 , when concentrations of each PCB congener increased, but overestimated the non contamination phase from day 84 to

21 168, when concentrations of each PCB congener decreased (Fig. 7a to d). The regression 22 between simulated and measured concentrations of all congeners showed a good correlation $23\left(\mathrm{y}=1.10 \mathrm{x}, \mathrm{R}^{2}=0.78\right)$ when we focused on the accumulation phase, whereas this correlation was poorer for the non contamination phase $\left(y=1.05 \mathrm{x}, \mathrm{R}^{2}=0.57\right)$ (Fig. 9a). The relationships 
1 between measured and simulated PCB during the non contamination phase showed equivalent

2 slopes for all PCB congeners (Fig. 9b).

The model respected the relative concentrations of each PCB congener: the concentration of CB153 in food was approximately twice that of CB149 and CB118, which were twice that of CB105 (Table 1). We found the same proportions in modelled PCB concentrations; at the end of the contamination phase (84 days), measured concentrations peaked at $94 \mathrm{ng} \cdot \mathrm{g}^{-1}$ wet weight for CB105, $183 \mathrm{ng} \cdot \mathrm{g}^{-1}$ for CB118 and CB149, and $348 \mathrm{ng} \cdot \mathrm{g}^{-1}$ for CB153 (Fig. 7a to d). As modelled males systematically had a lower total wet weight than females (Fig. 6b), simulated PCB concentrations in males were systematically higher than in females (Fig. 7). Unfortunately, as the fish were grouped for PCB concentration measurements, we were unable to make a comparison with observations.

\section{DISCUSSION}

\subsection{Parameter values}

We used the same model as that developed for four flatfish species by van der Veer et al. (2001), but improved it on several points. Firstly, contrary to the previous model that focused specifically on females, we took both males and females into account and used different values for certain parameters that we considered as being different in each sex according to the DEB theory ( $\kappa, V p$ and reproduction costs). This distinction is relevant when dealing with contaminants (see next paragraph). Secondly, in the previous model,

21 reproduction occurred from year one onwards (van der Veer et al., 2001, Fig. 7), whereas in our version, reproduction was only possible when fish reached a given length (corresponding to $V p$ ), corresponding to year two for both sexes. It is generally reported that maturity is reached at 3-4 years for female sole and 2 years for males (Deniel, 1981; Bromley, 2003). 
1 reached their maturity volume $\left(V_{p}\right)$ at 1.26 years, versus females at 1.96 years, hence just

2 before their third year. Consequently, a slight change in initial conditions or parameter values

3 would lead to a mature age for females in accordance with the literature. In addition to these small changes to the model design, we paid particular attention to the estimation of parameter values. We used the most widely-available data from the literature and calibrated several parameters independently. Some parameter values were taken directly

7 from van der Veer et al. (2001): $y_{E X}$ (for in situ applications only) and $\left[E_{G}\right]$. Others differed

8 just slightly with this study: $\delta,\left[E_{m}\right]$ and $\left[p_{M}\right]$ and some were clearly different, with

9 differences ranging from 25 to $500 \%$ for $\kappa, T A$ and $V p$ (Table 4). In our investigation, we accounted for environmental variations by taking into account variable temperatures in the calibration process when dealing with in situ data. The model with updated parameter values matched better to in situ data than the simulations performed using the previous model (van der Veer et al., 2001, Fig. 7), in particular because our model outputs were compared to a larger number of observations, such as total wet weight, and the model was applied and partially validated on an independent data set on the basis of experiments in controlled conditions. We concluded that the parameter values used in our study represented sole biology better than previously estimated parameters. Model application to our juvenile growth curves did however show a slight overestimation of length data in both experiments. $f$ values were calibrated on wet weight data, which was consequently more accurately simulated than length. According to the equation we used to estimate total wet weight in function of length, reserve and gonad weights, length mismatches may be due to the fact that the $\delta$ value was slightly underestimated, or that reproduction, for instance, was not well formulated in the model. Nevertheless, model simulations globally matched experimental data well. 


\subsection{Bioaccumulation model and potential PCB elimination}

The advantage of our bioaccumulation model is that it did not require any additional calibration as it depended directly on the growth model and on PCB concentrations in food, which were measured. Model outputs showed PCB concentrations to be systematically higher in males than in females of the same age. In sole, the $\kappa$ value was lower in males than in females, leading to slower growth in males. Consequently, at the same age and with identical food density, males weighed less and therefore showed higher contaminant levels than females. In situ sampling has shown that PCB concentrations in European hake are also higher in males than in females of the same length (Bodiguel et al., 2009). The estimated $\kappa$ value was also lower in males for this species. As a result, when males and females of the same length were compared, the males were found to be older and had accumulated more contaminants, resulting in higher PCB concentrations.

As no PCB effect was observed on growth measurements (see 4.4), contaminants only bioaccumulated and were not excreted in the model; consequently, the decrease in PCB concentrations in the model simulations was due to contaminant dilution through growth alone. PCB quantities remained constant from the time we ceased to administer spiked food, whereas the fish continued to grow, leading to decreasing concentrations of all congeners. Thus, if sole are capable of shifting from a contaminated to a "healthy" nursery in the natural environment, juvenile growth clearly constitutes a means of decontamination. Nevertheless, although model simulations accurately reproduced the increase in PCB concentrations during the accumulation phase (days 0-84), they overestimated measured PCB concentrations during the non contamination phase (days 84-168): the regression between simulated and measured concentrations of all congeners showed a good correlation when we focused on the accumulation phase, whereas this correlation was poorer for the non contamination phase.

This overestimation of PCB concentrations during the non contamination period could 
suggest that growth dilution was not the only route of decontamination for sole in our experiments and that other mechanisms of PCB elimination are present in this fish species. PCB elimination from fish body has already been suggested by several authors. In a similar study on seabass (Dicentrarchus labrax) involving 10 PCB congeners, including CB105 and CB118, the generic model used also overestimated total body concentration of PCB within a factor between 1.5 and 7 times of the measurements (Antunes et al. 2008). Our results showed that the relationships between measured and simulated PCB during the non contamination phase exhibited equivalent slopes for all PCB congeners. This could suggest identical elimination rates for each congener, without necessarily meaning the elimination processes are identical. However, CB153 is recognized as a highly persistent and stable PCB, making its elimination nearly impossible. Several studies reported its elimination from fish tissue. In an experimental study on mullet (Mugil cephalus), Antunes et al. (2007b) demonstrated a decrease of $95 \%$ of CB153 concentration in muscle and of $50 \%$ in liver in 249 days of experiment after providing unspiked food to fish. As fish mean weight decreased during the experiment, this decrease in CB153 concentration can not be due to dilution by growth. CB153 elimination has also been demonstrated on another flatfish species (flounder, Platichthys flesus), where CB153 quantity exponentially decreased in function of elimination time (Goerke and Weber, 2001), as well as on S. solea (Boon, 1985). Contrary to our results, which suggested identical elimination rates among the 4 PCB congeners tested, both earlier investigations on flatfishes demonstrated that lower levels of chlorination and also number and type of unsubstituted vicinal positions favoured elimination. Nevertheless, it has to be noted that PCB administration, mixture and concentrations were clearly different among studies, which certainly affects accumulation and elimination patterns. Our observations also revealed a higher dispersion of measured PCB concentrations during the non contamination phase versus the contamination phase. This dispersion may be 
1 due to differences in PCB elimination mechanisms between the sexes. For example, on

2 sampling day 140, when group 2 comprised males only and groups 1 and 3 comprised a

3 mixture of males and females, measured PCB concentrations were up to twice as high in

4 groups 1 and 3 versus group 2 (Fig. 8b). This experimental result countered our model

5 expectations of higher PCB concentrations in males due to lower $\kappa$ values and thus lower

6 weights. Nevertheless, as observed wet weights were not clearly different between the 3

7 groups (Fig. 8a), this difference in PCB concentrations could not originate from weight differences. We can hence conclude that males showed lower PCB concentrations as they have a better capacity to eliminate PCBs. Unfortunately, this comparison was only feasible on this particular sampling day, as sex differentiation was only possible from sampling day 112 onwards, and all other groups from day 112 onwards comprised a mixture of both sexes. Our conclusion contradicts that of Bodiguel et al. (2009) who reported higher measured PCB concentrations in male hakes. It has been shown that PCB elimination rates in sardines may differ according to sex and to the considered PCB congener (Antunes et al., 2007a), hence making the analysis of these results more complicated. However, PCB elimination processes may also differ according to species.

Comparisons between model simulations and observations proved to be complicated, as the model described an average individual and, for analytical convenience, PCB measurements were obtained with grouped fish. We hence calculated PCB concentrations according to the mean weight of the group; however, if two fish of very different weights were sampled from the same group, the measured PCB concentration of that group would not be representative of the individual fish or of the mean of the 2 fish. For example, the mean weights of 2 groups on sampling day 168 were different: $54 \pm 23 \mathrm{~g}$ for G1 and $63 \pm 15 \mathrm{~g}$ for G2, and the measured concentration of congener CB153 was twice as high for G1 than for G2

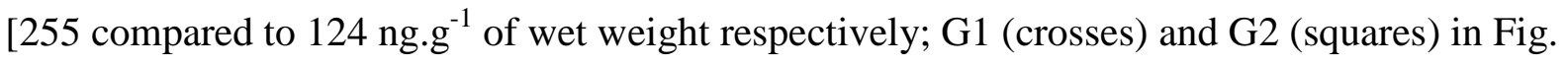


1 8]. Each group comprised 8 fish for PCB measurements; however, weights ranged from 36 to

$2107 \mathrm{~g}$ in $\mathrm{G} 1$ and from 47 to $87 \mathrm{~g}$ in $\mathrm{G} 2$. This data scatter, mainly due to initial variations in

3 reared sole and to individual variations in feeding, may also have contributed to the

4 difficulties encountered in relating biometric data to PCB measurements in our study. We

5 therefore suggest using tagged fish to obtain individual growth curves. This approach is

6 currently used in similar experiments. We will then obtain individual simulated growth curves

7 by estimating a value for $f$ for each fish, as was done in this study for each tank. This resulted

8 in a higher $f$ value for the PCB tank $(f=0.74)$ compared to the $\mathrm{C}$ tank $(f=0.68)$, suggesting that

9 fish raised in the PCB tank ate more (compared to uncontaminated fish) to compensate for

10 energy costs associated with PCB elimination and would explain why growth curves were

11 identical in both tanks. Nevertheless, individual growth curves would be easier to interpret.

12 This approach would also be of major interest for the study of bioaccumulation, as the exact

13 concentrations of each congener would be known in any fish at any given time, hence

14 facilitating comparison with model predictions.

\subsection{Model improvements}

The growth model accurately fitted the growth curves obtained from in situ sampling as well as from experiments in controlled conditions using the same parameter set. However, experimental data only concerned juvenile sole; as a result, longer experiments are needed to fully validate the sole growth model. In our study, male and female data could not be

21 differentiated. Experiments on adults are necessary to validate the parameters that differed between the sexes, such as $\kappa$. In addition, we only obtained a small amount of information on reproduction, mainly focusing on females. Several studies have focused on the various aspects of sole reproduction. These studies (1) have described the factors influencing maturity (de Veen, 1976; Ramsay, 1993), (2) have helped to determine the effect of temperature on 
1 spawning (Deniel, 1981; Devauchelle et al., 1987; Rijnsdorp et al., 1992; Vinagre et al., 2008)

2 and (3) have determined spawning duration (Deniel, 1981; Anonyme 1992). This information

3 could be reproduced mathematically to improve knowledge on energy allocation to

4 reproduction and used to calibrate the parameters associated with this function. Nevertheless,

5 our study provided promising results; it showed that the same model can be applied to

6 different situations and encouraged the development of additional applications for the energy

7 allocation model. Using the DEB theory is advantageous as, once the model is fully validated,

8 we will be able to compare model parameters with other fish species and compare the

9 mechanisms governing contaminant accumulation and elimination in different organisms.

We showed that our model failed to reproduce PCB concentrations during the non

11 contamination phase, probably because it did not take into account a process of PCB

12 elimination from the organism. More experiments are needed to understand the processes responsible for this PCB elimination from fish tissue, which should then be incorporated in the model. Fonds et al. (1995) revealed that PCBs were present in the eggs of female dabs in different proportions to those supplied in food. This suggests that different PCB congeners are assimilated with different efficiencies and eliminated through a variety of processes, due to their different chemical properties and structures. It has indeed been shown that the assimilation and excretion of PCBs depend on their $\log \mathrm{K}_{\mathrm{ow}}$ (octanol-water partition coefficient). This could easily be accounted for by adding a new module in which, for example, assimilation efficiency is a direct function of the $\log \mathrm{K}_{\mathrm{ow}}$ value of the congener, as 21 has already been done in various modelling studies on contaminant kinetics (Thomann et al., 1992; Antunes et al., 2008; Baas et al., 2009; Jager and Kooijman, 2009). The same effort should be made to model PCB elimination from fish tissue. Although we suggested that sole were able to excrete PCBs, our growth curves did not reveal any significant differences between the $\mathrm{C}$ and PCB tanks. This indicates that elimination occurred either without any cost 
1 for sole, or that the use of optimal conditions for our experiments enabled a sort of "cost

2 compensation". Further investigations are therefore necessary to identify what processes are responsible for this potential PCB elimination and what costs it implies for sole.

adults are necessary to measure the elimination of PCBs during spawning, then compare the results with model predictions. Bodiguel et al. (2009) demonstrated that PCB concentrations measured in female hakes in the Gulf of Lions were lower and more scattered than those found in male hakes. They modelled this phenomenon by allowing PCB elimination during spawning, whereby the degree of decontamination was higher in females due to the high lipid content of eggs compared to male sperm. This type of model could also be tested for sole.

\subsection{Effects of PCBs on growth}

The comparison of growth rates from the $\mathrm{C}$ and PCB tanks showed that the administration of PCB congeners CB105, CB118, CB149 and CB153 at the given concentrations and during the 3-month exposure period did not affect juvenile sole growth. Similarly, PCB contamination did not markedly affect dab growth (Fonds et al., 1995) or Arctic charr growth (Jørgensen et al., 1999) during laboratory experiments. PCBs have been found to have no impact on lipid deposition and mobilisation (Jørgensen et al., 1999). In our study, however, it appeared that the lipid weights of fish in the PCB tank were higher than those in the $\mathrm{C}$ tank (data not shown); however, little data on lipids was acquired for the control experiment, so our conclusion should be taken with precaution. Previous studies have indicated that PCB components can be redistributed among fish organs according to exchange equilibria (Boon et al., 1984; Antunes et al., 2008), with a possible contaminant exchange between muscle and liver in mullet, and that PCB elimination processes may differ according to organs (Antunes et al., 2007b). Our results contradict a previous study that showed 
1 significantly lower growth in contaminated sole (Boon, 1985); however, this study used a

2 different mixture of PCBs in different concentrations, which may explain the variations in 3 results.

\section{CONCLUSION}

Our study allowed a considerable improvement of DEB parameterisation. Consistency between experimental observations and model simulations during the contamination phase confirmed that bioaccumulation is related to feeding and growth, whereas discrepancies between observations and model during the non contamination phase can not be explained by the dilution effect alone and suggested the existence of other elimination mechanisms of

11 PCBs. However, the variability of responses in measured PCB concentrations implies to consider individual growth monitoring. This approach is currently used in similar and longer experiments, and will also enable to differentiate mechanisms of PCB accumulation and elimination between sexes. 
2 We would like to thank the French Agence National de la Recherche (ANR) for validating 3 the SoleBeMol project (project nº ANR-06-PVULN-O13. - IFREMER N07/2.210 210/F.)

4 used to fund this study. We are grateful to V. Buchet, O. Gastineau and N. Le Bayon for

5 taking care of the cultures on a daily basis and helping with sampling. The authors also thank

6 the AquaDEB research group for their ideas on conducting this investigation. We would like

7 to thank the two anonymous reviewers for their comments, which helped to substantially

8 improve the manuscript. We finally thank J. Purcell, from Sea Pen Scientific Writing LLC,

9 and L. Valentine for their help in English correction.

10

11

12

13

14

15

16

17

18

19

20

21

22

23

24

25 
2 Abarnou, A., Loizeau, V., 1994. La bioaccumulation: l'exemple des PCB. Oceanis 20, 29-45.

Able, K.W., 1999. Measures of fish habitat quality: Examples from a national estuarine research reserve. In: Benaka, L. R. (Ed), Fish Habitat: essential fish habitat and rehabilitation. American Fisheries Society, Symposium. Vol 22, Bethesda, Maryland, pp. 134-147.

Ahlborg, U.G., Hanberg, A., 1994. Toxic equivalency factors for dioxon-like PCBs. Environ. Sci. Pollut. Res. Int. 1, 67-68.

Alunno-Bruscia, M., van der Veer, H.W., Kooijman, S.A.L.M., 2009. The AquaDEB project (phase I): Analysing the physiological flexibility of aquatic species and connecting physiological diversity to ecological and evolutionary processes by using Dynamic Energy Budgets. J. Sea Res. 62, 43-48. doi:10.1016/j.seares.2009.07.005.

Anonyme, 1992. Report of the study group on the fecundity of sole and plaice in sub areas IV, VII and VIII. ICES CM1992/G:16.

Antunes, P., Amado, J., Vale, C., Gil, O., 2007a. Influence of the chemical structure on mobility of PCB congeners in female and male sardine (Sardina pilchardus) from Portuguese coast. Chemosphere 69, 395-402. doi:10.1016/j.chemosphere.2007.04.084.

Antunes, P., Gil, O., Ferreira, M., Vale, C., Reis-Henriques, M.A., 2007b. Depuration of PCBs and DDTs in mullet under captivity clean conditions. Chemosphere 67, S58S64. doi:10.1016/j.chemosphere.2006.05.091.

Antunes, P., Hendriks, A.J., Huijbregts, M.A.J., Gil, O., Reis-Henriques, M.A., 2008. Organspecific accumulation and elimination patterns of PCBs in adult seabass (Dicentrarchus labrax). Sci. Total Environ. 407, 204-210.

Baas, J., Jager, T., Kooijman, S.A.L.M., 2009. A model to analyze effects of complex mixtures on survival. Ecotoxicol. Environ. Saf. 72, 669-676. 
1 Bodiguel, X., Maury, O., Mellon-Duval, C., Roupsard, F., Le Guellec, A.M., Loizeau, V., 2009. A dynamic and mechanistic model of PCB bioaccumulation in the European hake (Merluccius merluccius). J. Sea Res. 62, 124-134. doi:

10.1016/j.seares.2009.02.006.

Bodin, N., Abarnou, A., Le Guellec, A.M., Loizeau, V., Philippon, X., 2007. Organochlorinated contaminants in decapod crustaceans from the coasts of Brittany and Normandy (France). Chemosphere 67, S36-S47.

Boon, J.P., 1985. Uptake, distribution, and elimination of selected PCB components of Clophen A40 in juvenile sole (Solea solea) and effects on growth. In: Gray, J. S., Christiansen, M. E. (Eds), Marine biology of polar regions and effects of stress on marine organisms, John Wiley \& Sons Ltd., Chichester, pp. 493-512.

Boon, J.P., Oudejans, R.C.H.M., Duinker, J.C., 1984. Kinetics of indiviual polyChlorinated biphenyl (PCB) components in juvenile sole (Solea solea) in relation to their concentrations in food and to lipid metabolism. Comp. Biochem. Physiol. CPharmacol. Toxicol. Endocrinol. 79, 131-142.

Bourlès, Y., Alunno-Bruscia, M., Pouvreau, S., Tollu, G., Leguay, D., Arnaud, C., Goulletquer, P., Kooijman, S.A.L.M., 2009. Modelling growth and reproduction of the Pacific oyster Crassostrea gigas: Advances in the oyster-DEB model through application to a coastal pond. J. Sea Res. 62, 62-71. doi:10.1016/j.seares.2009.03.002.

Bromley, P.J., 2003. The use of market sampling to generate maturity ogives and to investigate growth, sexual dimorphism and reproductive strategy in central and southwestern North Sea sole (Solea solea L.). ICES J. Mar. Sci. 60, 52-65.

Claireaux, G., Désaunay, Y., Akcha, F., Aupérin, B., Bocquené, G., Budzinski, H., Cravedi, J.P., Davoodi, F., Galois, R., Gilliers, C., Goanvec, C., Guérault, D., Imbert, N., Mazéas, O., Nonnotte, G., Nonnotte, L., Prunet, P., Sébert, P., Vettier, A., 2004. 
Influence of oil exposure on the physiology and ecology of the common sole Solea solea: Experimental and field approaches. Aquat. Living Ressour. 17, 335-351.

Costanza, R., d'Arge, R., de Groot, R., Farber, S., Grasso, M., Hannon, B., Limburg, K., Naeem, S., O'Neill, R.V., Paruelo, J., Raskin, R.G., Sutton, P., van den Belt, M., 1997. The value of the world's ecosystem services and natural capital. Nature 387, 253-260. de Veen, J.F., 1976. On changes in some biological parameters in the North Sea sole (Solea solea L.). ICES/CIEM International Council for the Exploration of the Sea 37, 60-90.

Deniel, C., 1981. Les poissons plats (téléostéens, Pleuronectiformes) en Baie de Douarnenez. Reproduction, croissance et migration des Bothidae, Scophtalmidae, Pleuronectidae et Soleidae. PhD thesis, Université de Bretagne Occidentale, pp. 476.

Devauchelle, N., Alexandre, J.C., Le Corre, N., Letty, Y., 1987. Spawning of sole (Solea solea) in captivity. Aquac. 66, 125-147.

Eichinger, M., Kooijman, S.A.L.M., Sempéré, R., Lefèvre. D., Grégori, G., Charrière, B., Poggiale, J.C., 2009. DOC consumption and release by marine bacteria in pulsedsubstrate environment: from experiments to modelling. Aquat. Microb. Ecol. 56, 4154.

Foekema, E.M., Deerenberg, C., Murk, A.J., 2008. Prolonged ELS test with the marine flatfish sole (Solea solea) shows delayed toxic effects of previous exposure to PCB 126. Aquat. Toxicol. 90, 197-203.

Fonds, M., Casal, E., Schweizer, D., Boon, J.P., van der Veer, H.W., 1995. Effects of PCB contamination on the reproduction of the dab Limanda limanda L. under laboratory conditions. Neth. J. Sea Res. 34 (1-3), 71-79.

Fonds, M., Drinkwaard, B., Resink, J.W., Eysink, G.G.J., Toet, W., 1989. Measurements of metabolism, food intake and growth of Solea solea (L.) fed with mussel meat or with dry food. In: De Pauw, N., Jaspers, E., Ackefors, H., Wilkins, N. (Eds), Aquaculture - 
A biotechnology in progress, European Aquaculture Society, Bredene (Belgium), pp. 851-874.

Fonds, M., Saksena, V.P., 1977. The daily food intake of young soles (Solea solea) in relation to their size and the water temperature. 3rd Meeting of the ICES Working Group on Mariculture Brest, France, pp. 51-58.

Freitas, V., Cardoso, J.F.M.F., Santos, S., Campos, J., Drent, J., Saraiva, S., Witte, J.I.J., Kooijman, S.A.L.M., van der Veer, H.W., 2009. Reconstruction of food conditions for Northeast Atlantic bivalve species based on Dynamic Energy Budgets. J. Sea Res. 62, 75-82. doi:10.1016/j.seares.2009.07.004.

Fry, F.E., 1971. The effect of environmental factors on the physiology of fish. In: Hoar, W. S., Randall, D. J. (Eds), Fish physiology. Vol VI, Academic Press, New York, pp. 198.

Goerke, H, Weber, K., 2001. Species-specific elimination of polychlorinated biphenyls in estuarine animals and its impact on residue patterns. Mar. Environ. Res. 51:131-149.

Grangeré, K., Ménesguen, A., Lefebvre, S., Bacher, C., Pouvreau, S., 2009. Modelling the influence of environmental factors on the physiological status of the Pacific oyster Crassostrea gigas in an estuarine embayment; The Baie des Veys (France). J. Sea Res. 62, 147-158. doi:10.1016/j.seares.2009.02.002.

Hofelt, C., Shea, D., 1997. Accumulation of organochlorine pesticides and PCBs by semipermeable membrane devices and Mytilus edulis in New Bedford harbor. Environ. Sci. Technol. 31, 154-159.

Imsland, A.K., Foss, A., Conceição, L.E.C., Dinis, M.T., Delbare, D., Schram, E., Kamstra, A., Rema, P., White, P., 2003. A review of the culture potential of Solea solea and S. senegalensis. Rev. Fish Biol. Fish. 13, 379-407. 
1 Ivanciuc, T., Ivanciuc, O., Klein, D.J., 2006. Modeling the bioconcentration factors and bioaccumulation factors of polychlorinated biphenyls with posetic quantitative superstructure/activity relationships (QSSAR). Mol. Divers. 10, 133-145.

Jager, T., Kooijman, S.A.L.M., 2009. A biology-based approach for quantitative structureactivity relationships (QSARs) in ecotoxicity. Ecotoxicol. 18, 187-196.

Jaouen-Madoulet, A., Abarnou, A., Le Guellec, A.M., Loizeau, V., Leboulenger, F., 2000. Validation of an analytical procedure for polychlorinated biphenyls, coplanar polychlorinated biphenyls and polycyclic aromatic hydrocarbons in environmental samples. J. Chromatogr. A 886, 153-173.

Jørgensen, E.H., Bye, B.E., Jobling, M., 1999. Influence of nutritional status on biomarker responses to PCB in the Arctic charr (Salvelinus alpinus). Aquat. Toxicol. 44, 233244.

Kooijman, S.A.L.M., 2000. Dynamic energy and mass budgets in biological systems. $2^{\text {nd }}$ edition. Cambridge University Press, Cambridge, pp. 424.

Koutsikopoulos, C., Dorel, D., Désaunnay, Y., 1995. Movement of sole (Solea solea) in the Bay of Biscay : coastal environment and spawning migration. J. Mar. Biol. Assoc. U.K. 75, 109-126.

Lefrançois, C., Claireaux, G., 2003. Influence of ambient oxygenation and temperature on metabolic scope and heart rate of the common sole (Solea solea). Mar. Ecol. Prog. Ser. 259, 273-284.

Loizeau, V., Abarnou, A., Cugier, P., Jaouen-Madoulet, A., Le Guellec, A.M., Menesguen, A., 2001. A model of PCB bioaccumulation in the seabass food web from the Seine estuary (eastern English Channel). Mar. Pollut. Bull. 43, 242-255. 
1 Maury, O., Faugeras, B., Shin, Y.J., Poggiale, J.C., Ben Ari, T., Marsac, F., 2007. Modeling environmental effects on the size-structured energy flow through marine ecosystems. Part 1: The model. Prog. Oceanogr. 74, 479-499. doi:10.1016/j.pocean.2007.05.002.

Mole, A., Norcross, B.L., 1998. Effects of oil-laden sediments on growth and health of juvenile flatfishes. Can. J. Fish. Aquat. Sci. 55, 605-610.

Pecquerie, L., Petitgas, P., Kooijman, S.A.L.M., 2009. Modeling fish growth and reproduction in the context of the Dynamic Energy Budget theory to predict environmental impact on anchovy spawning duration. J. Sea Res. 62, 93-105. doi:10.1016/j.seares.2009.06.002.

Pouvreau, S., Bourlès, Y., Lefebvre, S., Gangnery, A., Alunno-Bruscia, M., 2006. Application of a dynamic energy budget model to the Pacific oyster, Crassostrea gigas, reared under various environmental conditions. J. Sea Res. 56, 156-167. doi:10.1016/j.seares.2006.03.007.

Quiniou, L., 1986. Les peuplements de poissons démersaux de la pointe de Bretagne. PhD thesis, Université de Bretagne Occidentale, pp. 350.

Ramsay, K., 1993. Factors influencing first time maturity in female sole (Solea solea (L.)). ICES CM1993/G:25.

Rashleigha, B., Barbera, M.C., Waltersb, D.M., 2009. Foodweb modeling for polychlorinated biphenyls (PCBs) in the Twelvemile Creek Arm of Lake Hartwell, South Carolina, USA. Ecol. Model. 220, 254-264.

Richard, P., Djabali, M., Lagardère, F., Lagardère, J.P., 1983. Etude de la composition corporelle de la sole (Solea solea) au cours du jeûne: influence de la température. In: Bases biologiques de l'aquaculture. Vol 1, IFREMER. Actes de Colloques, Montpellier., pp. 429-436. 
1 Rijnsdorp, A.D., Van Beek, F.A., Flatman, S., Millner, R.M., Riley, J.D., Giret, M., De Clerck, R., 1992. Recruitment of sole stocks, Solea solea (L.), in the northeast Atlantic. Neth. J. Sea Res. 29:173-192.

Riou, P., Le Pape, O., Rogers, S.I., 2001. Relative contributions of different sole and plaice nurseries to the adult population in the Eastern Channel: application of combined method using generalized linear models and a geographic information system. Aquat. Living Resour. 14, 125-135.

Schram, E., Van der Heul, J.W., Kamstra, A., Verdegem, M.C.J., 2006. Stocking densitydependent growth of Dover sole (Solea solea). Aquac. 252, 339-347.

Smith, A.K., Suthers, I.M., 1999. Effects of sewage effluent discharge on the abundance, condition and mortality of hulafish, Trachinop taeniatus (Plesiopidae). Environ. Pollut. 106, 97-106.

Szlinder-Richert, J., Barska, I., Mazerski, J., Usydus, Z., 2009. PCBs in fish from the southern Baltic Sea: Levels, bioaccumulation features, and temporal trends during the period from 1997 to 2006. Mar. Pollut. Bull. 58, 85-92.

Thomann, R.V., Connolly, J.P., 1984. Model of PCB in the Lake Michigan lake trout food chain. Environ. Sci. Technol. 18, 65-71.

Thomann, R.V., Connolly, J.P., Parkerton, T.F., 1992. An equilibrium-model of organicchemical accumulation in aquatic food webs with sediment interaction. Environ. Toxicol. Chem. 11, 615-62.

van der Veer, H.W., Kooijman, S.A.L.M., ven der Meer, J., 2001. Intra- and interspecies comparison of energy flow in North Atlantic flatfish species by means of dynamic energy budgets. J. Sea Res. 45, 303-320. 
1 Vinagre, C., Amara, R., Maia, A., Cabral, H.N., 2008. Latitudinal comparison of spawning season and growth of 0-group sole, Solea solea (L.). Estuar. Coast. Shelf Sci. 78, 521-

3 528.

4

5

6

7

8

9

10

11

12

13

14

15

16

17

18

19

20

21

22

23

24

25 
1 Table 1. Conditions in each experimental tank and concentrations of each PCB congener

2 included in sole food. C and PCB are control and Polychlorinated biphenyl tanks respectively.

\begin{tabular}{|c|c|c|}
\hline Tank name & $\mathbf{C}$ & PCB \\
\hline \multicolumn{3}{|l|}{ Initial conditions } \\
\hline Fish density $\left(\mathrm{kg} . \mathrm{m}^{-2}\right)$ & 2.3 & 1.8 \\
\hline Initial length $(\mathrm{cm})$ & $12,4 \pm 1,4$ & $12,0 \pm 1,3$ \\
\hline Initial total wet weight $(\mathrm{g})$ & $19,2 \pm 6,1$ & $16,0 \pm 4,6$ \\
\hline \multicolumn{3}{|c|}{ Physico-chemical parameters } \\
\hline $\begin{array}{l}\text { Temperature } \\
{\left[\mathrm{O}_{2}\right]} \\
\text { Photoperiod light:dark (h) }\end{array}$ & $\begin{array}{r}19^{\circ} \mathrm{C} \\
>80 \% \\
12: 12 \\
\end{array}$ & $\begin{array}{r}19^{\circ} \mathrm{C} \\
>80 \% \\
12: 12 \\
\end{array}$ \\
\hline \multicolumn{3}{|l|}{ Food } \\
\hline $\begin{array}{l}\text { amount } \\
\text { composition } \\
{[\mathrm{PCB}] \mathrm{ng}^{-1} \text { of food }} \\
{[\mathrm{CB} 105]} \\
{[\mathrm{CB} 118]} \\
{[\mathrm{CB} 149]} \\
{[\mathrm{CB} 153]}\end{array}$ & $\begin{array}{c}\text { ad libitum } \\
\text { no solvent, no PCB } \\
\\
0 \\
0 \\
0 \\
0 \\
\end{array}$ & $\begin{array}{c}\text { ad libitum } \\
+ \text { solvent }+ \text { PCB } \\
\\
228 \\
454 \\
420 \\
888 \\
\end{array}$ \\
\hline \multicolumn{3}{|l|}{ Measurements } \\
\hline $\begin{array}{l}\text { Biometry } \\
\text { Total length } L(\mathrm{~cm}) \\
\text { Total wet weight } W_{W}(\mathrm{~g}) \\
\text { Number of fish per sample } \\
\text { Sampling days }\end{array}$ & $\begin{array}{c}\mathrm{x} \\
\mathrm{x} \\
33 \pm 14 \\
0,4,8,28,56,84,88 \\
\end{array}$ & $\begin{array}{c}\mathrm{x} \\
\mathrm{x} \\
34 \pm 13 \\
98,112,140, \text { and } 168 \\
\end{array}$ \\
\hline \multicolumn{3}{|l|}{ Chemical analyses in muscle } \\
\hline $\mathrm{CB} *(\mathrm{ng})$ & & $\mathrm{x}$ \\
\hline Number of fish per sample & & $\begin{array}{l}\text { triplicates ( } 3 \text { groups) } \\
4 \text { to } 11 \\
\text { fish/measurement }\end{array}$ \\
\hline
\end{tabular}


1 Table 2. Symbols and notations used in the growth and bioaccumulation models for sole.

\begin{tabular}{|c|c|c|}
\hline Symbol & Units & Description \\
\hline \multicolumn{3}{|r|}{ Notation } \\
\hline$\dot{p}_{*}$ & $\mathrm{~J} . \mathrm{d}^{-1}$ & Flux of compound $*$ \\
\hline\{\} & J.cm ${ }^{-2}$ & $\begin{array}{l}\text { Surface-area-specific } \\
\text { parameters }\end{array}$ \\
\hline [ ] & $\mathrm{J} . \mathrm{cm}^{-3}$ & $\begin{array}{l}\text { Volume-specific } \\
\text { parameters }\end{array}$ \\
\hline \multicolumn{3}{|r|}{ Processes } \\
\hline$X$ & & Ingestion \\
\hline$A$ & & Assimilation \\
\hline$M$ & & Maintenance \\
\hline$G$ & & Growth \\
\hline$C$ & & Mobilisation/Catabolism \\
\hline$J$ & & Maturity \\
\hline$R$ & & Reproduction \\
\hline
\end{tabular}

2

3

4

5

6

7

8

9

10

11

12

13

14

15

16

17 
1 Table 3. Symbols, units, values and description of state and forcing variables used for sole

2 growth and bioaccumulation models. The last column shows the formulae used to compare

3 model outputs and data. Please refer to Table 4 for parameter description.

\begin{tabular}{|c|c|c|c|c|}
\hline Symbol & Units & Value & Description & $\begin{array}{c}\text { Comparison with } \\
\text { data }\end{array}$ \\
\hline \multicolumn{5}{|c|}{ State variables } \\
\hline$V$ & $\mathrm{~cm}^{3}$ & & Structural volume & $V=(\delta L)^{3}$ \\
\hline$E$ & $\mathbf{J}$ & & Reserve energy & $E=\mu_{E} W_{E}$ \\
\hline$E_{R}$ & $\mathbf{J}$ & & Reproduction buffer & $E_{R}=\mu_{G^{*}} W_{G}$ \\
\hline$C B_{f i s h}^{*}$ & ng & & $\begin{array}{l}\text { Quantity of } \mathrm{CB}^{*} \text { in } \\
\text { fish }\end{array}$ & \\
\hline$\left[C B^{*}\right]_{f i s h}$ & $n g \cdot g^{-1}$ & & $\begin{array}{l}\text { Concentration of } \\
\mathrm{CB}^{*} \text { in fish }\end{array}$ & {$\left[C B^{*}\right]_{f i s h}=\frac{C B_{f i s h}^{*}}{W_{W}}$} \\
\hline$L$ & $\mathrm{~cm}$ & & Total length & $L=\frac{V^{1 / 3}}{\delta}$ \\
\hline$W_{E}$ & g & & Weight of reserve & $W_{E}=\frac{E}{\mu_{E}}$ \\
\hline$W_{G}$ & g & & Weight of gonads & $W_{G}=\frac{E_{R}}{\mu_{G^{*}}}$ \\
\hline$W_{W}$ & g & & Total wet weight & $W_{W}=V+W_{E}+W_{G}$ \\
\hline \multicolumn{5}{|c|}{\begin{tabular}{|c|} 
Forcing variables \\
\end{tabular}} \\
\hline$f$ & - & $\begin{array}{l}\text { Deniel (1981): } 0.70 \\
\text { C tank: } 0.68 \\
\text { PCB tank: } 0.74\end{array}$ & Food density & \\
\hline $\mathrm{T}$ & $\mathrm{K}$ & $\begin{array}{l}\text { Deniel }(1981): 281<\mathrm{T}<291 \\
\left(=8^{\circ} \mathrm{C}<\mathrm{T}<18^{\circ} \mathrm{C}\right) \\
\text { this study: } 292\left(=19^{\circ} \mathrm{C}\right)\end{array}$ & Temperature & \\
\hline
\end{tabular}


1 Table 4. Description, units, values [compared with those of van der Veer et al. (2001)] and

2 route of parameter estimation used for sole growth and bioaccumulation models.

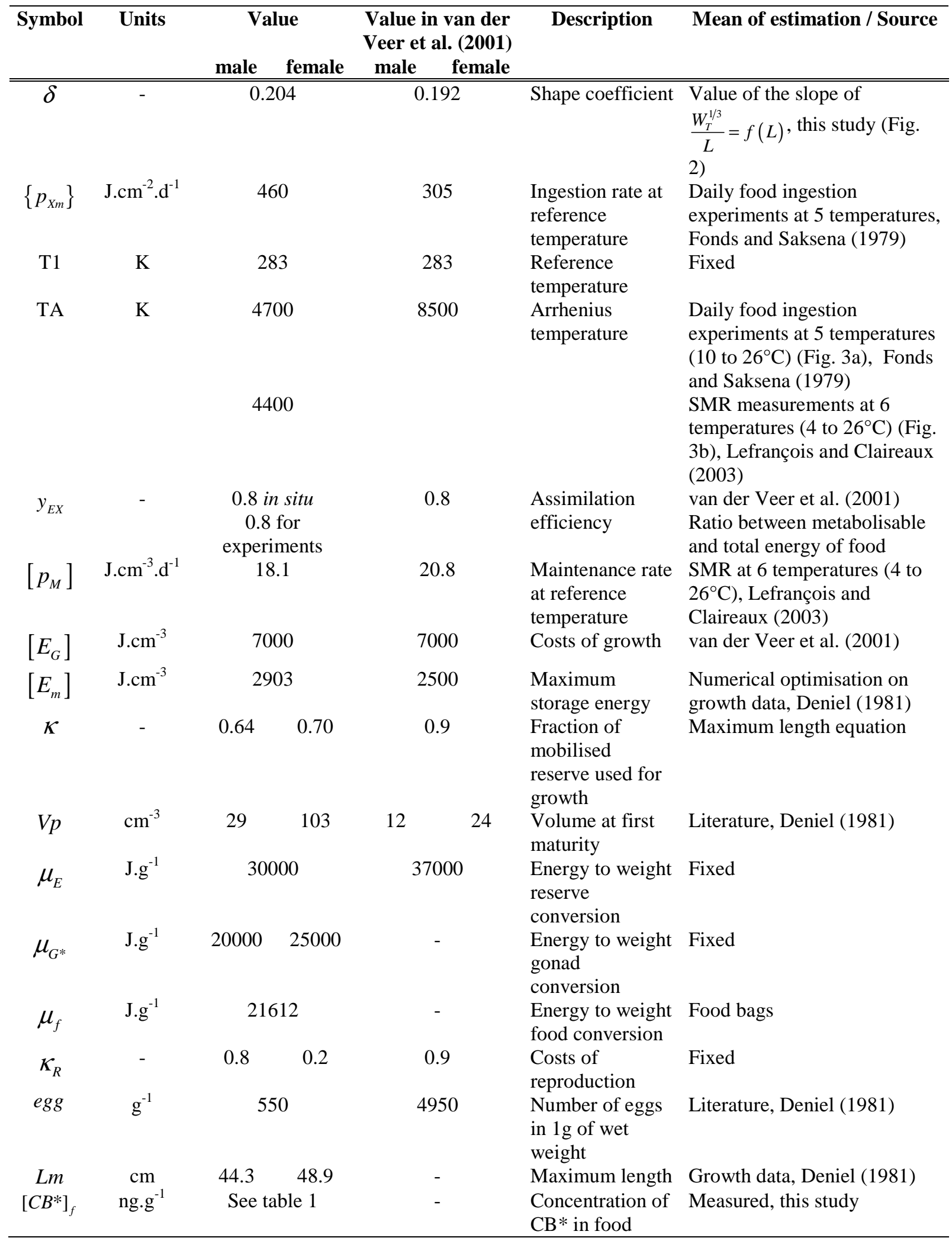


3 Figure 1. Diagram of the sole growth model and PCB distribution (grey ellipses) in the model.

4 Ellipses are proportional to assimilation efficiency (Table 4). The square boxes indicate state

5 variables, the round boxes indicate sources or sinks. The grey arrows and boxes represent

6 reproduction not taken into account in the bioaccumulation model. Energy fluxes through an

7 organism are: $\dot{p}_{X}=$ ingestion, $\dot{p}_{A}=$ assimilation, $\dot{p}_{C}=$ reserve utilisation, $\dot{p}_{M}=$ maintenance

8 (structural volume), $\dot{p}_{G}=$ growth, $\dot{p}_{J}=$ maturity maintenance, $\dot{p}_{R}=$ development or

9 reproduction. See Tables 2 and 3 for descriptions of notations and state variables.

11 Figure 2. Representation of $\delta$ (shape coefficient) values as a function of sole length

$12\left(\delta=\frac{W_{W}^{1 / 3}}{L}\right)$. The graph represents the $\delta$ estimation for each sampled fish from the control (C) tank. Because the $\delta$ value was then used to convert the modelled volume (structure without reserve) to length, we used $\delta$ values from thinner fish only, assuming these values to be in the lower third. The circles (o) represent fish which were not used for $\delta$ estimation as they were assumed to comprise structure and reserve. The crosses (+) represent fish used for $\delta$ estimation. The slope of the solid line for these soles is 0.204 .

19 Figure 3. $\left\{\dot{p}_{X_{M}}\right\}$ (a) and $\left[p_{M}\right]$ (b) variations as functions of temperature. The crosses (+) or

20 crosses \pm sd represent experimental values of $\left\{\dot{p}_{X_{M}}\right\}$ and $\left[p_{M}\right]$ estimated from Fonds and

21 Saksena (1977) and Lefrançois and Claireaux (2003) respectively. We used the formulae

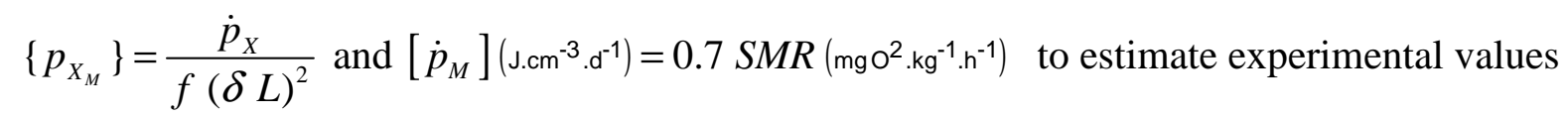


$1 \quad \dot{p}_{*(T)}=\dot{p}_{*(T 1)} \exp \left(\frac{T A}{T 1}-\frac{T A}{T}\right)$, whereby $\dot{p}_{*(T)}$ is the rate $\left(\left\{\dot{p}_{X_{M}}\right\}\right.$ or $\left.\left[\dot{p}_{M}\right]\right)$ at the actual

2 temperature $T$ [eq. (9)] and with the estimated $T A$ value for each experiment (Table 4$)$. The

3 dashed lines (--) represent simulations of the same equation with an intermediate value of

$4 T A=4550 \mathrm{~K}$. Temperatures are in degrees Kelvin in the formulae but in Celsius in the figures.

6 Figure 4. Model simulations versus sole growth and reproduction data (Deniel, 1981) for total 7 length (a), total wet weight (b), gonad weight (c) and annual egg production (d). The circles

8 (०) and transverse crosses (x) represent data for females and males respectively. The solid (-)

9 and dashed (--) lines represent model simulations for females and males respectively. The

10 vertical crosses (+) represent female wet weight estimated using the size-weight relationship

11 given by Deniel (1981). Model simulations for reproduction (c and d) were obtained with one

12 model output per year ( $\square$ ), just prior to reproduction, and compared to reproduction data given by Deniel (1981), represented by vertical crosses (+).

Figure 5. Growth in length (a) and weight (b) for juvenile sole reared in the control tank. The crosses (+) represent measured mean lengths or weights \pm standard deviation. The solid (-) and dashed lines (--) represent model simulations for females and males respectively. The growth model is described by eq. (2-8). Descriptions of state variables and parameter values are shown in Tables 3 and 4, respectively.

Figure 6. Growth in length (a) and weight (b) for juvenile sole reared in the PCB tank. The crosses (+) represent measured mean lengths or weights \pm standard deviation. The solid (-) and dashed lines (--) represent model simulations for females and males respectively. The growth model is described by eq. (2-8). Descriptions of state variables and parameter values are shown in Tables 3 and 4, respectively. 
2 Figure 7. Kinetics of the concentrations (ng. $\mathrm{g}^{-1}$ of wet weight) of 4 PCB congeners: CB105 (a), CB118 (b), CB149 (c), and CB153 (d) as measured in sole tissues (+) from the PCB tank and simulated by the bioaccumulation model [eq. $(10-11)$ ] coupled to the growth model [eq. (2-8)] for females (solid lines) and males (dashed lines). The 4 PCB congeners were included in food (Table 1). Each cross represents one PCB measurement on a group of fish (three replicates at each sampling time).

Figure 8. Model simulations for male sole (dashed lines) compared to experimental data on total wet weight (a) and [CB153] (ng.g ${ }^{-1}$ wet weight) (b) of sole from the PCB tank. Experimental data are represented as the mean \pm standard deviation of PCB measurements for each group. Each symbol (o, $\square$ or + ) represents the same group for total wet weight and [CB153] at a given sampling time. For better visibility, the symbols o and + have been shifted by - and +2 days respectively from the sampling day. Model simulations are the same as those shown in Figs. 6 and 7.

Figure 9. Comparisons between measured and simulated concentrations (ng. $\mathrm{g}^{-1}$ of wet weight) of all PCB congeners during the contamination (+) and non contamination (o) phases. For each comparison, we plotted regression lines (by forcing the 0 crossing) to check the accuracy of the fit, and obtained the following relationships and correlation coefficients: $y=1.10 \mathrm{x}$ $\left(\mathrm{R}^{2}=0.78\right.$, solid line $)$ for the contamination phase and $\mathrm{y}=1.05 \mathrm{x}\left(\mathrm{R}^{2}=0.57\right.$, dashed line $)$ for the non contamination phase (a). Focus on the comparisons between measured and simulated PCB concentrations (ng. $\mathrm{g}^{-1}$ of wet weight) in the non contamination phase for each PCB congener: CB105 (৩), CB118 (x), CB149 (o) and CB153 ( $\square)$. We also plotted regression lines (without forcing the 0 crossing) and obtained the following relationships and correlation 
1 coefficients: $y=0.33 x+54.1\left(R^{2}=0.56\right.$, dashed line $)$ for $C B 105, y=0.32 x+107.6\left(R^{2}=0.54\right.$,

2 solid line) for $\mathrm{CB} 118, \mathrm{y}=0.34 \mathrm{x}+98.4\left(\mathrm{R}^{2}=0.55\right.$, dashed-dotted line $)$ for $\mathrm{CB} 149$ and $\mathrm{y}=0.36 \mathrm{x}$ $3+208.9\left(\mathrm{R}^{2}=0.52\right.$, dotted line $)$ for CB153 (b).

4

5

6

7

8

9

10

11

12

13

14

15

16

17

18

19

20

21

22

23

24

25 
1 Figure 1 (Eichinger et al., 2010)

2

3

4

5

6

7

8

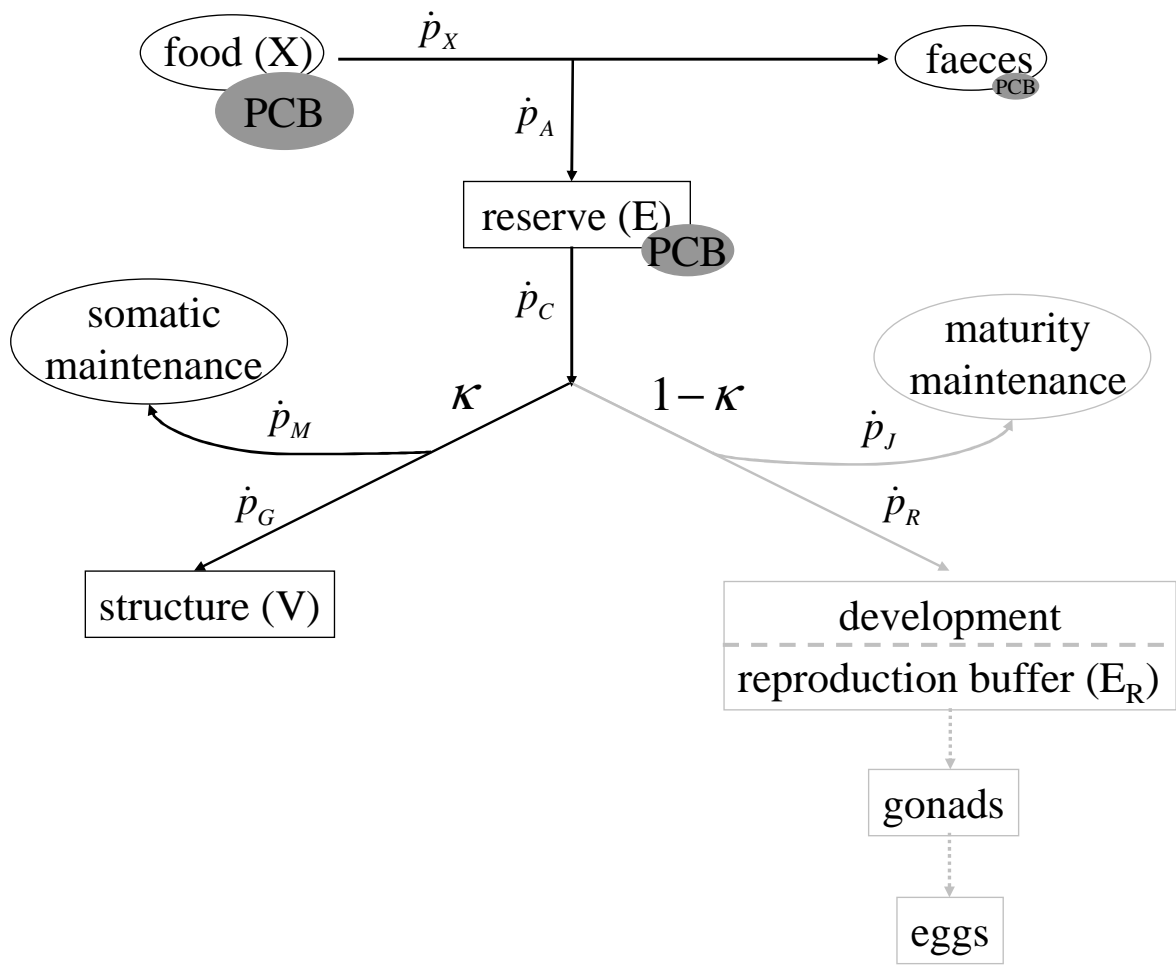

10

11

12

13

14

15

16 
Figure 2 (Eichinger et al., 2010)

2

3

4

5

6

7

8

9

10

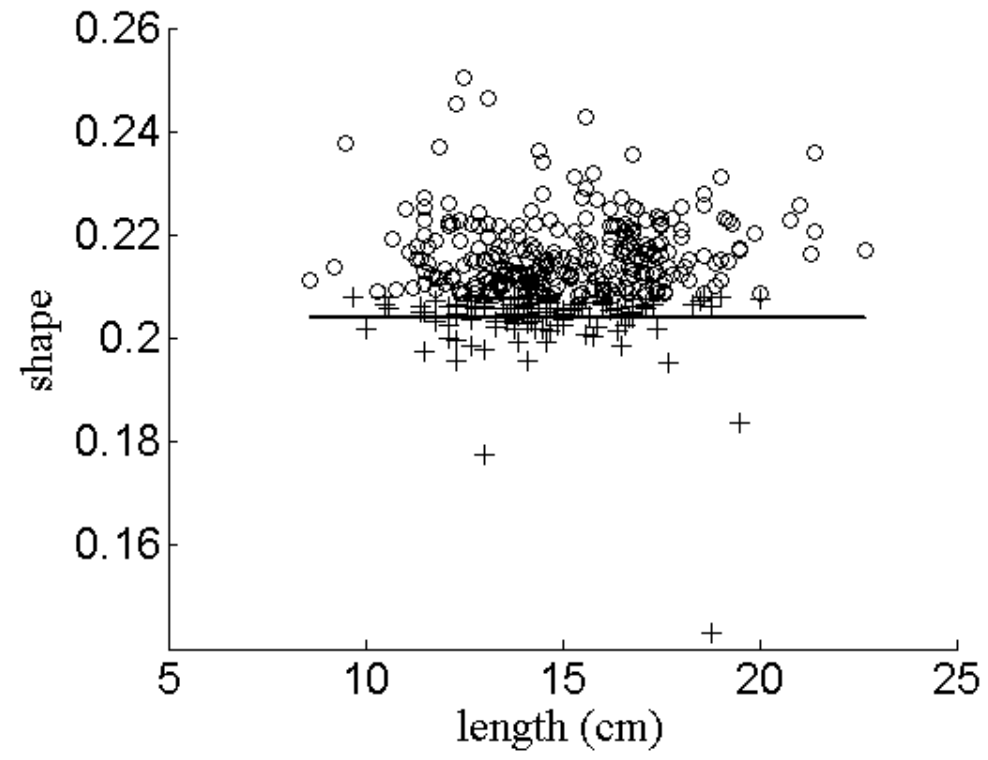

11

12

13

14

15

16

17

18 


\section{Figure 3 (Eichinger et al., 2010)}

2

3

4

5

6

7

8

9

10

11
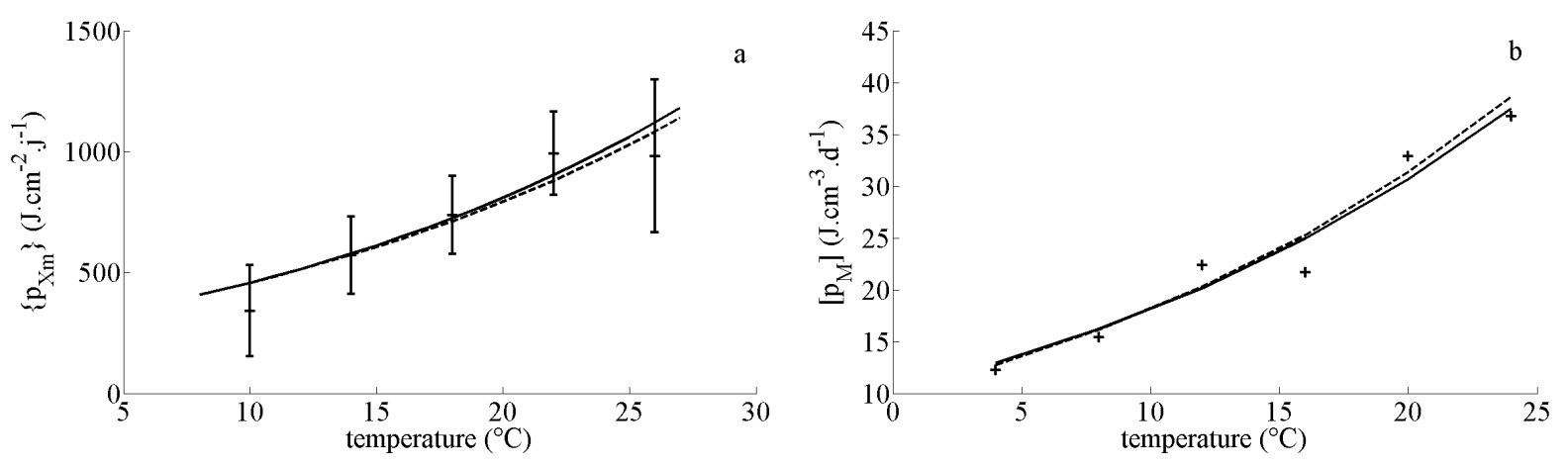

12

13

14

15

16

17

18

19

20

21 
1 Figure 4 (Eichinger et al., 2010)

2

3

4

5

6

7

8
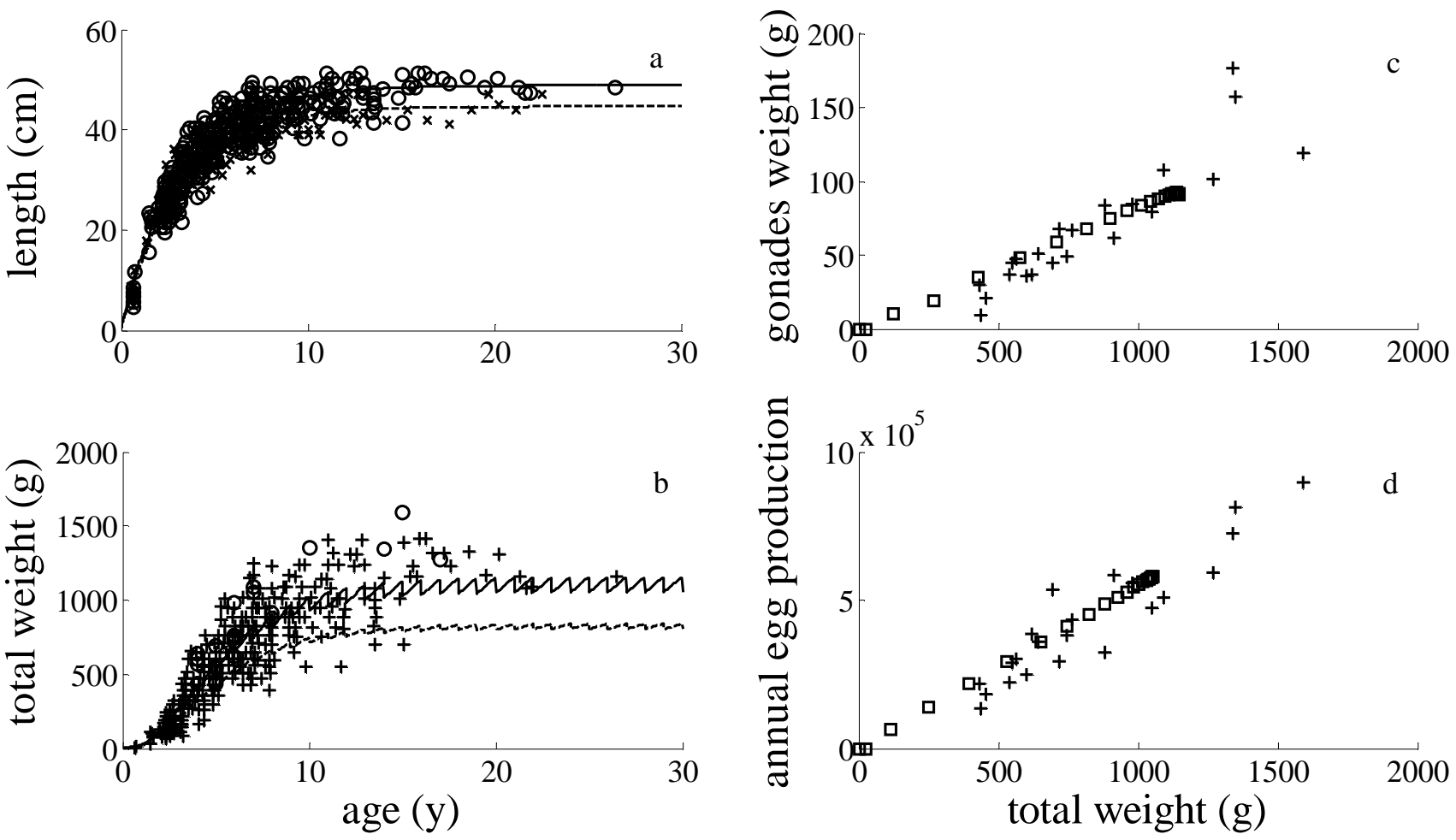
1 Figure 5 (Eichinger et al., 2010)

2

3

4

5

6

7

8

9

10
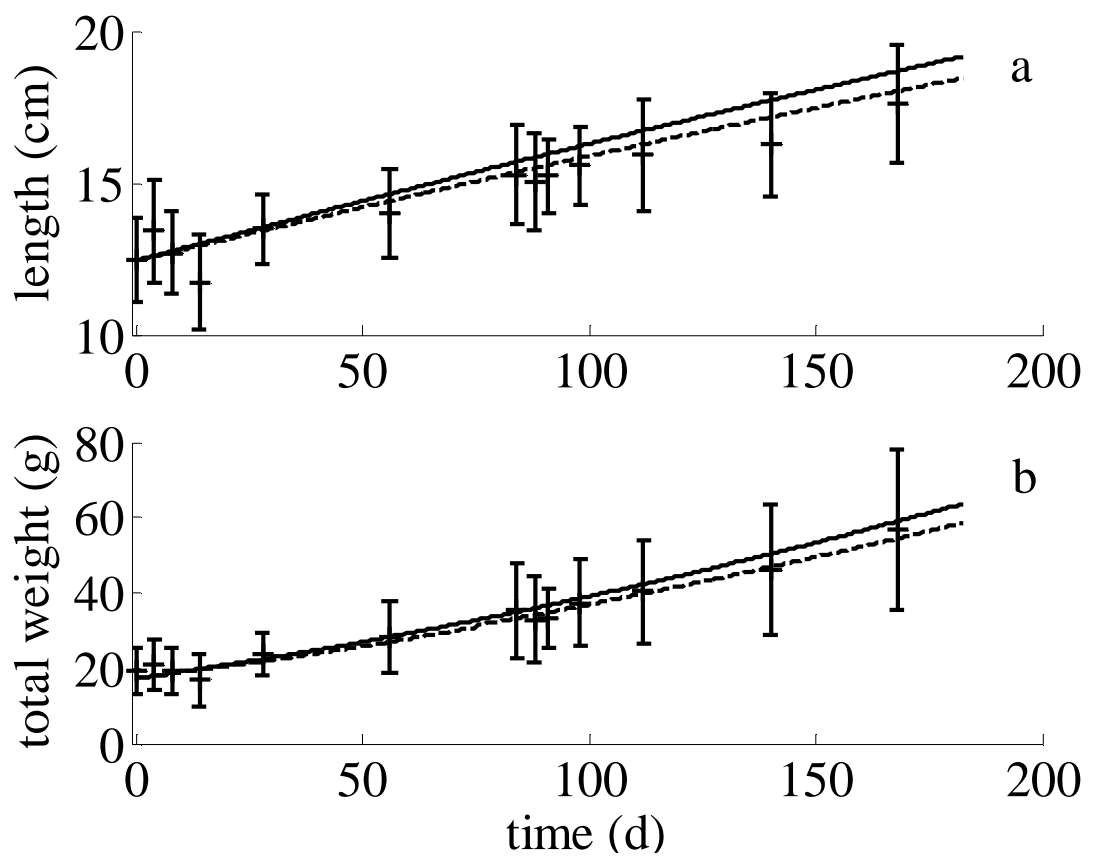

11

12

13

14

15

16

17 
1 Figure 6 (Eichinger et al., 2010)

2

3

4

5

6

7

8

9
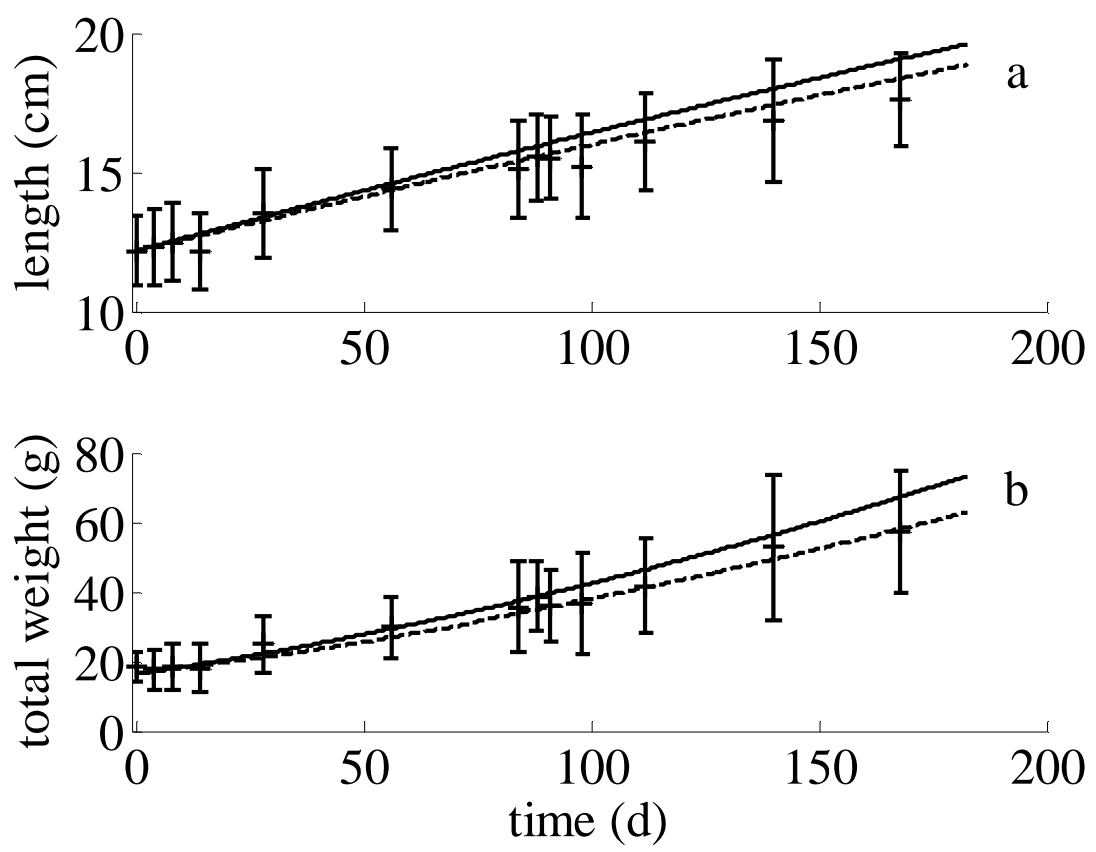

10

11

12

13

14

15

16

17 
Figure 7 (Eichinger et al., 2010)

2

3

4

5

6

7

8
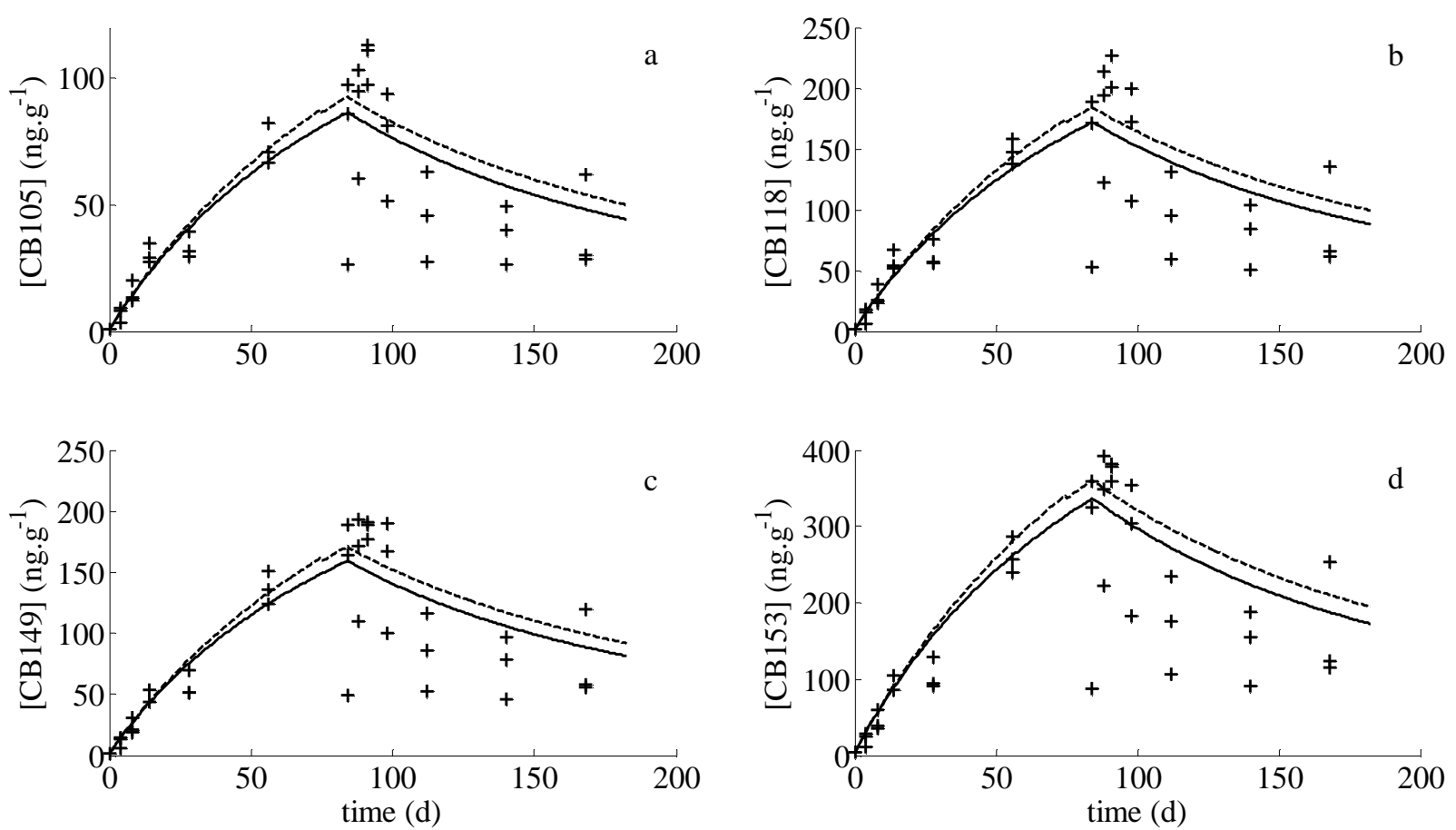

9

10

11

12

13

14

15

16 
1 Figure 8 (Eichinger et al., 2010)

2

3

4

5

6

7

8
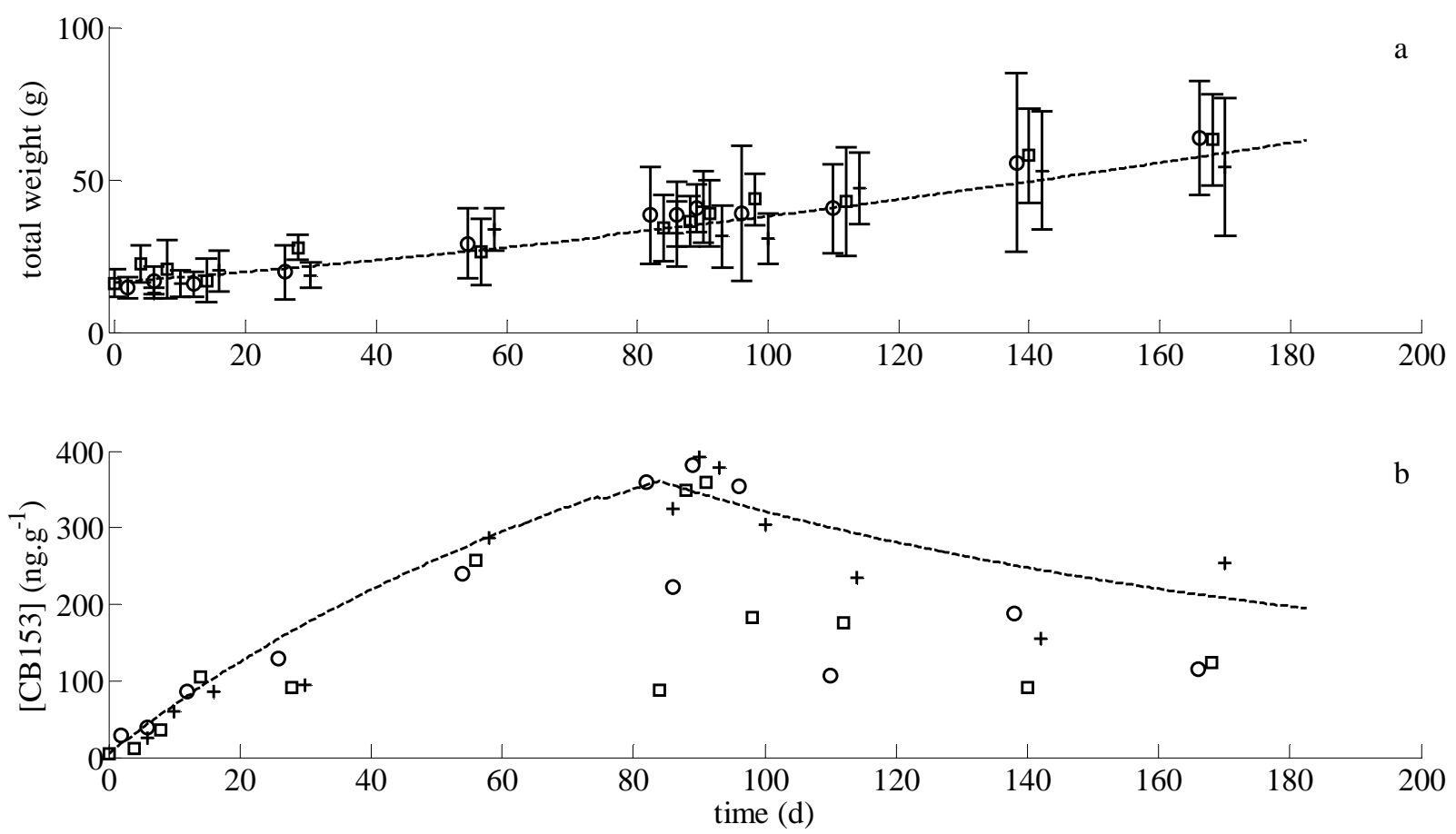

9 
Figure 9 (Eichinger et al., 2010)

2

3

4

5

6

7
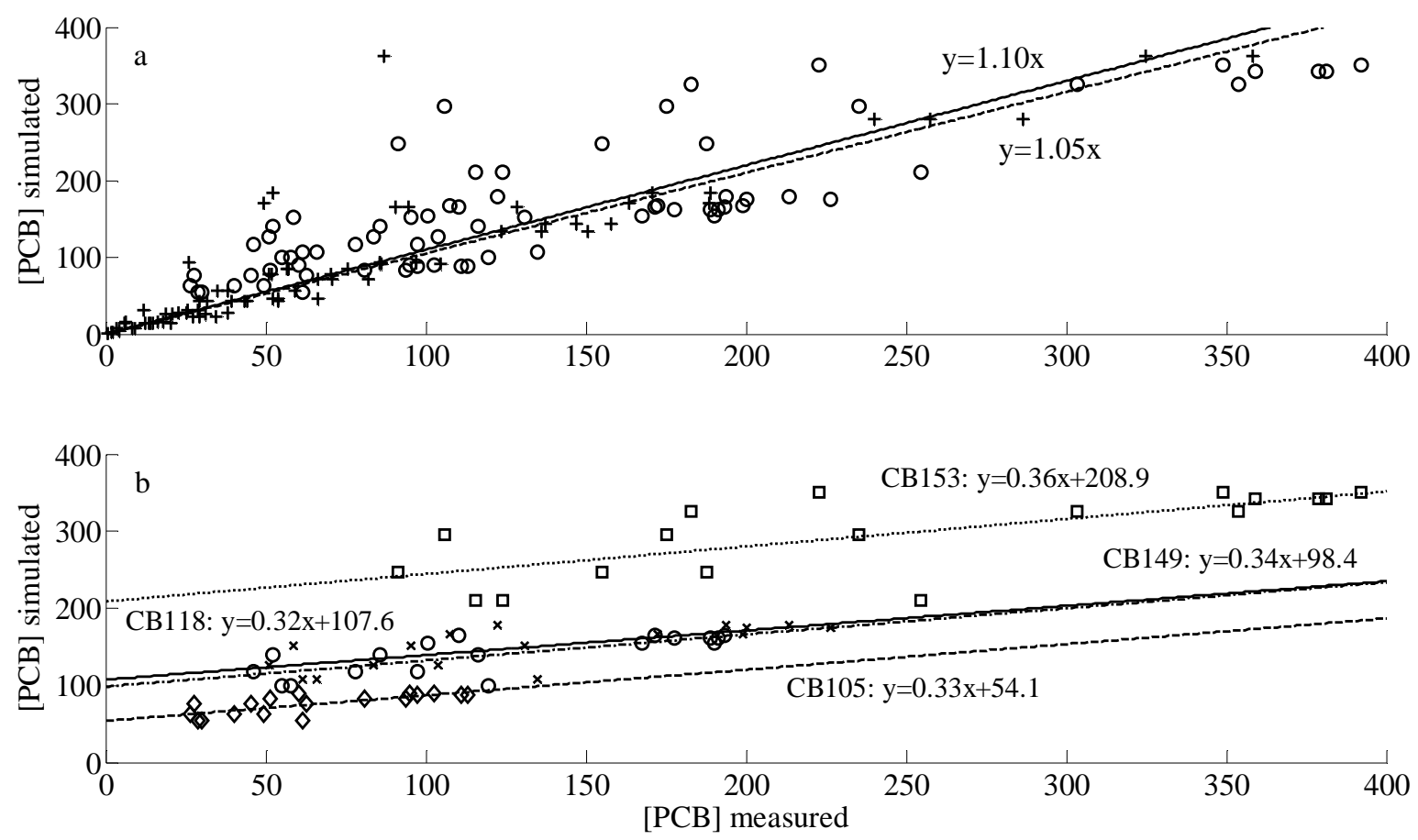

9 